\title{
CAPACIDADES DINÂMICAS BASEADAS EM CONHECIMENTO E TIPOS DE INOVAÇÃO: PROPOSIÇÃO DE UM FRAMEWORK DE ANÁLISE
}

\section{Mateus Panizzon}

Doutorando em Administração pela em associação ampla da Universidade de caxias - USC e Pontifícia Universidade Católica do Rio Grande do Sul - PUC/RS

MPanizzo@ucs.br (Brasil)

\section{Gabriel Sperandio Milan}

Doutor em Engenharia de Produção na Área de Sistemas de Qualidade pela Universidade Federal do Rio Grande do Sul - UFRGS

Professor e pesquisador da Universidade de Caxias do Sul - USC

gsmilan@ucs.br (Brasil)

\section{Marcelo Gattermann Perin}

Doutor em Administração pela Universidade Federal do Rio Grande do Sul - UFRGS

Professor e Pesquisador da Pontifícia Universidade Católica do Rio Grande do Sul - UFRGS mperin@ pucrs.br (Brasil)

\section{Cláudio Hoffmann Sampaio}

Doutor em Administração pela Universidade Federal do Rio Grande do Sul - UFRGS

Professor e Pesquisador da Pontifícia Universidade Católica do Rio Grande do Sul - UFRGS csampaio@pucrs.br (Brasil)

\section{RESUMO}

As Capacidades Dinâmicas (CD) consistem um conceito bastante desenvolvido e pesquisado na área de Estratégia, mas que, no entanto, evidenciam uma falta de uniformidade em sua definição e dimensões componentes quando abordadas pelos diferentes autores. Esta pesquisa tem como objetivo propor um framework de análise das Capacidades Dinâmicas Baseadas em Conhecimento (CDBC) e os distintos tipos de Inovação, construído a partir da síntese de estudos tipo survey desenvolvidos analisando a relação entre as CDBC e desempenho de inovação. Partindo-se das categorias identificados por Denford (2013) para compreensão deste e por meio da estratégia de análise de conteúdo, buscou-se identificar a dimensões associadas, de que forma foram operacionalizadas e que tipo de relação foi encontrada. Como resultado, após discussão das convergências e divergências entre as abordagens de $\mathrm{CDBC}$, este trabalho propõe um framework para orientar pesquisas futuras entre CDBC e Inovação, o Modelo Unificado das Capacidades Dinâmicas Baseadas em Conhecimento.

Palavras-chave: VBC - Visão Baseada em Conhecimento; Capacidades dinâmicas; Capacidades dinâmicas baseadas em conhecimento; Recursos; Inovação; Desempenho de inovação. 


\section{INTRODUÇÃO}

As Capacidades Dinâmicas (CD) consistem em um conceito bastante desenvolvido e pesquisado na área de estratégia (Hodgkinson \& Healey, 2011), mas que evidenciam uma falta de uniformidade ou de consenso em sua definição e dimensões componentes quando abordadas pelos autores (Denford, 2013). Stefano, Peteraf e Verona (2014) ressaltam que há uma confusão em torno do construto em si, e o exercício de definição é importante para o avanço na área. Em síntese, as CD, no seu conceito original, consistem na habilidade da empresa em integrar, construir e reconfigurar competências internas e externas para se adequar a ambientes dinâmicos (Teece, Pisano, \& Shuen, 1997), ainda mais quando predominantemente tecnológicos (Smart, Bessant, \& Gupta, 2007), e se materializam em rotinas que ajudam a manipular as configurações de recursos e capacidades em processos de criação de valor e desenvolvimento de produtos (Eisenhardt \& Martin, 2000).

As CD surgiram como uma evolução ao conceito da VBR - Visão Baseada em Recursos (RBV - Resource-based View) e ao conceito de VBC - Visão Baseada em Conhecimento (KBV Knowledge-based View). Aliás, para Grant (1996) e Zollo e Winter (2002), o conhecimento é o principal elemento que contribui na criação das CD das empresas (firmas). Isso porque é a partir da recombinação das capacidades atuais e de seus recursos disponíveis, principalmente do conhecimento, enquanto recurso intangível, que uma possível vantagem competitiva é obtida. É nessa perspectiva da VBC que emerge o conceito de Capacidades Dinâmicas Baseadas em Conhecimento.

Teece (2009) apresenta um posicionamento de modo a diferenciar capacidades dinâmicas e competências, pertinente para justificar a pesquisa neste tema: "Uma empresa genérica com competências/recursos mas sem capacidades dinâmicas irá, em equilíbrio, "se manter", produzindo e vendendo o mesmo produto, na mesma escala, e para o mesmo mercado". Portanto, para o autor, competências estão associadas com a manutenção do status quo, onde nenhuma atividade inovadora existe, e é classificada como gerenciamento operacional. Dito isso, o estudo das Capacidades Dinâmicas é relevante dado o ambiente turbulento que demanda maior capacidade de inovação da organização para atingir vantagem competitiva sustentável.

Denford (2013) identificou cerca de 80 exemplos de CDBC - Capacidades Dinâmicas Baseadas em Conhecimento (KBDC - Knowledge-based Dynamic Capabilities), observando uma nomenclatura fragmentada e sem um framework conceitual dominante. Contudo, o autor observa que há sete frameworks (estruturas de análise ou modelos) que apresentam determinada consistência, mas que evidenciam um conflito em nomenclatura e nas dimensões associadas. Havendo, portanto, diferentes definições sobre este mesmo construto, as CDBC, emerge o problema de que em pesquisas 
que relacionam as CDBC com a inovação, por exemplo, estar-se-ia medindo fenômenos diferentes, ou o mesmo fenômeno com medidas diferentes, o que implicaria na dificuldade de comparação, relação e convergência, buscando um desenvolvimento teórico mais consistente em torno desta temática.

Com esta problemática, o presente estudo tem como objetivo central propor um Modelo Unificado das Capacidades Dinâmicas Baseadas em Conhecimento, enquanto um framework de referência para facilitar a compreensão do tema e orientar futuras pesquisas na definição e seleção dos construtos a serem utilizados. Para este objetivo, buscou-se desenvolver uma análise com base em com base em estudos realizados do tipo survey que relacionam as CDBC ao Desempenho de Inovação, em diferentes tipologias. Partindo-se das categorias propostas por Denford (2013), esta pesquisa busca identificar quais foram os construtos utilizados, de que forma foram operacionalizados e que tipo de relação foi encontrada. Com isso, estabelece-se um mapeamento das diferentes abordagens inerentes às CDBC e seus resultados encontrados, em um esforço de síntese, identificando convergências e divergências entre elas.

\section{REFERENCIAL TEÓRICO}

\subsection{Capacidades Dinâmicas (CD) e suas Tipologias}

Considerando a delimitação do tema deste artigo, as CD não serão relacionadas à VBR, mas sim à VBC, que é uma evolução deste primeiro conceito. A partir do momento em que o conhecimento é um recurso intangível chave, e uma das principais fontes para a construção e consolidação de uma vantagem competitiva sustentável (Acedo, Barroso, \& Galan, 2006; Conner \& Prahalad, 1996; Ray, Barney, \& Muhanna, 2004), o papel da empresa não é de simplesmente adquirir recursos (como prega a RBV) e capacidades, mas desenvolver o conhecimento organizacional a partir de seu acesso e sua integração, por meio de rotinas e de processos para produzir possíveis vantagens competitivas (Grant, 1996; Barrales-Molina, Bustinga \& Gutiérrez-Gutiérrez, 2012).

Contudo, se o conhecimento é criado e mantido pelos indivíduos, os processos de criação e de transferência de conhecimento são essenciais para o desenvolvimento do conhecimento organizacional como um ativo estratégico e uma fonte de vantagem competitiva (Grant, 1996; Von Krogh, Nonaka, \& Aben, 2001). Isso porque há a necessidade de se estabelecer uma diferenciação entre capacidades e recursos. Para Cepeda e Vera (2007), as capacidades são as competências da empresa de disponibilizar recursos, usando processos e recursos organizacionais, e tais capacidades são rotinas incorporadas e

Revista de Administração e Inovação, São Paulo, v.12, n.1, p.271-302, jan./mar. 2015. 
intangíveis, que não são facilmente separadas da empresa e, portanto, não podem ser trocadas no mercado (Kogut \& Zander, 1992). Contudo, uma capacidade pode ser operacional ou dinâmica. Enquanto a primeira consiste em um conjunto de rotinas que articulam inputs e outputs (Winter, 2000), as $\mathrm{CD}$ agem sobre as capacidades operacionais, mudando-as e reconfigurando-as (Zahra, Sapienza, \& Davidsson, 2006).

Todavia, na forma com que se manifestam as CD é que se observam diferentes interpretações e tipologias. A priori, a regra básica de uma tipologia é que estas classes (tipos) sejam mutuamente exclusivas (Hambrick, 1984), e na tentativa de identificar estas distinções, Denford (2013) delimitou sete frameworks, os quais foram propostos por Teece, Pisano e Shuen (1997), Eisenhardt e Martin (2000), Zahra e George (2002), Helfat e Peteraf (2003), Verona e Ravasi (2003), Rothaermel e Alexandre (2009) e Zheng, Zhang, Wu e Du (2011). De forma resumida, suas definições serão apresentadas no Quadro 1. O que se observa, em relação às tipologias, é a diferenciação nas dimensões utilizadas pelos diversos autores para explicar o construto, ainda que as definições sejam particularmente convergentes.

\begin{tabular}{|c|c|c|}
\hline Autores & Definições & Dimensões do Construto \\
\hline $\begin{array}{l}\text { Teece, Pisano } \\
\text { e Shuen (1997) }\end{array}$ & $\begin{array}{l}\text { Habilidade de integrar, } \\
\text { construir e reconfigurar } \\
\text { competências internas e } \\
\text { externas para se adaptar } \\
\text { rapidamente a ambientes } \\
\text { dinâmicos }\end{array}$ & $\begin{array}{l}\text { Construir: processo de aprender pela experimentação, o que } \\
\text { pode resultar em novo conhecimento; } \\
\text { Reconfigurar: reorganiza e combina ativos, estrutura e } \\
\text { capacidades; } \\
\text { Integrar: função de coordenação, transferindo e } \\
\text { internalizando a informação na organização; } \\
\text { Replicar/Imitar: repetir ou imitar ações anteriores bem } \\
\text { sucedidas. }\end{array}$ \\
\hline $\begin{array}{l}\text { Eisenhardt e } \\
\text { Martin (2000) }\end{array}$ & $\begin{array}{l}\text { Processos da firma que } \\
\text { usam recursos para } \\
\text { integrar, reconfigurar, } \\
\text { ganhar e lançar recursos } \\
\text { para se adequar às } \\
\text { mudanças de mercado }\end{array}$ & $\begin{array}{l}\text { Criação: rotinas de criação de conhecimento para construir } \\
\text { novas capacidades; } \\
\text { Integração: integração de recursos e habilidades de várias } \\
\text { partes da organização; } \\
\text { Reconfiguração: combina diferentes conhecimentos e } \\
\text { recursos existentes. }\end{array}$ \\
\hline $\begin{array}{l}\text { Zahra e George } \\
\qquad(2002)\end{array}$ & $\begin{array}{l}\text { As CD são geradas via } \\
\text { mudança organizacional, } \\
\text { são de natureza } \\
\text { estratégica e definem o } \\
\text { caminho da empresa em } \\
\text { termos de evolução e } \\
\text { desenvolvimento }\end{array}$ & $\begin{array}{l}\text { Transformação: refinamento das rotinas que permite } \\
\text { combinação do conhecimento existente aos novos } \\
\text { adquiridos; } \\
\text { Exploitation: rotina que permite a empresa a potencializar } \\
\text { competências existentes por meio de acesso a } \\
\text { conhecimentos de diferentes partes da organização; } \\
\text { Aquisição: identificação e aquisição de conhecimento } \\
\text { externo; } \\
\text { Assimilação: interpretar informação externa. }\end{array}$ \\
\hline $\begin{array}{l}\text { Helfat e Peteraf } \\
\qquad(2003)\end{array}$ & $\begin{array}{l}\text { Tomam por base o } \\
\text { conceito de Teece, Pisano } \\
\text { e Shuen (1997), mas } \\
\text { estabelecem novas } \\
\text { dimensões que } \\
\text { comporiam o construto } \\
\end{array}$ & $\begin{array}{l}\text { Recombinação: combinar buscando criar novas } \\
\text { capacidades ou conhecimentos; } \\
\text { Reconfiguração: das capacidades atuais buscando criar } \\
\text { novos produtos e/ou serviços; } \\
\text { Renovação: busca e desenvolvimento de alternativas; } \\
\text { Replicação: transferência parcial ou total de uma }\end{array}$ \\
\hline
\end{tabular}

Revista de Administração e Inovação, São Paulo, v.12, n.1, p.271-302, jan./mar. 2015. 


\begin{tabular}{|c|c|c|}
\hline & $(\mathrm{CD})$ & capacidade para outra região geográfica. \\
\hline $\begin{array}{l}\text { Verona e Ravasi } \\
\text { (2003) }\end{array}$ & $\begin{array}{c}\text { Conjunto de } \\
\text { competências que } \\
\text { permite a empresa criar } \\
\text { novos produtos e } \\
\text { processos, e responder às } \\
\text { circunstâncias e } \\
\text { mudanças do mercado }\end{array}$ & $\begin{array}{l}\text { Criação: novo conhecimento via pesquisa; } \\
\text { Reconfiguração: reorganização de sistemas e conhecimento } \\
\text { existente; } \\
\text { Integração: a partir do conhecimento latente de diversas } \\
\text { partes da organização. }\end{array}$ \\
\hline $\begin{array}{l}\text { Rothaermel e } \\
\text { Alexandre } \\
\text { (2009) }\end{array}$ & $\begin{array}{c}\text { Tomam por base o } \\
\text { conceito de Teece, Pisano } \\
\text { e Shuen (1997), mas } \\
\text { estabelecem novas } \\
\text { dimensões que } \\
\text { comporiam o construto } \\
\text { (CD) }\end{array}$ & $\begin{array}{l}\text { Quadrante I: fonte interna de conhecimento existente; } \\
\text { Quadrante II: fonte externa de conhecimento existente; } \\
\text { Quadrante III: fonte interna de nova tecnologia; } \\
\text { Quadrante IV: fonte externa de tecnologia existente. }\end{array}$ \\
\hline $\begin{array}{l}\text { Zheng, Zhang, } \\
\text { Wu e Du (2011) }\end{array}$ & $\begin{array}{l}\text { Tomam por base o } \\
\text { conceito de Teece, Pisano } \\
\text { e Shuen (1997), mas } \\
\text { estabelecem novas } \\
\text { dimensões que } \\
\text { comporiam o construto } \\
\text { (CD) }\end{array}$ & $\begin{array}{l}\text { Aquisição: identificação e transferência de conhecimento } \\
\text { de fontes externas; } \\
\text { Geração: atividades internas de geração de conhecimento; } \\
\text { Combinação: de conhecimentos. }\end{array}$ \\
\hline
\end{tabular}

Quadro 1: Principais conceitos de Capacidades Dinâmicas e suas dimensões Fonte: Adaptado de Denford (2013).

Nesta análise, pode-se observar que o elemento central da definição de CDBC envolve um conjunto de competências da empresa que, para se adequar a ambientes dinâmicos, busca estabelecer um conjunto de processos que agem sobre seus recursos. Nesta direção, Denford (2013) observou, portanto, oito tipos de CDBC (criação, integração, reconfiguração, replicação, desenvolvimento, assimilação, síntese e imitação) a partir da síntese de seu estudo dos autores anteriormente mencionados, conforme apresentado no Quadro 2, sendo os quatro primeiros com foco interno na empresa e os quatro últimos com foco externo.

A partir desta síntese, pode-se observar que as $\mathrm{CDBC}$, doravante neste estudo citadas simplesmente como CD, envolvem oito tipos de capacidades, cada uma com propostas, mecanismos, papel da gestão, impacto na empresa e benefícios distintos, o que possibilita oportunidades de pesquisa em termos da sua relação com a inovação. 


\begin{tabular}{|c|c|c|c|c|}
\hline \multirow{2}{*}{ Tipos } & \multicolumn{4}{|c|}{ Foco Interno } \\
\hline & Criação & Integração & Reconfiguração & Replicação \\
\hline Dimensões & $\begin{array}{c}\text { Exploração } \\
\text { Combinativa }\end{array}$ & $\begin{array}{c}\text { Exploração } \\
\text { Absortiva }\end{array}$ & $\begin{array}{l}\text { Exploitation } \\
\text { Combinativa }\end{array}$ & $\begin{array}{c}\text { Exploitation } \\
\text { Absortiva }\end{array}$ \\
\hline Proposta & $\begin{array}{l}\text { Exploração de novo } \\
\text { conhecimento } \\
\text { dentro da } \\
\text { empresa por } \\
\text { recombinação }\end{array}$ & $\begin{array}{l}\text { Reconhecer fontes } \\
\text { de conhecimento, } \\
\text { absorver e integrar } \\
\text { dentro da empresa }\end{array}$ & $\begin{array}{c}\text { Combina e } \\
\text { disponibiliza } \\
\text { recursos existentes } \\
\text { na empresa para } \\
\text { produzir vantagem } \\
\text { competitiva }\end{array}$ & $\begin{array}{l}\text { Reconhecer, } \\
\text { assimilar e aplicar } \\
\text { recursos existentes } \\
\text { em qualquer lugar } \\
\text { dentro da empresa }\end{array}$ \\
\hline Mecanismos & $\begin{array}{l}\text { Experimentação, } \\
\text { combinação e busca } \\
\text { de conhecimento }\end{array}$ & $\begin{array}{c}\text { Grupos de } \\
\text { integração, } \\
\text { socialização } \\
\text { vertical e } \\
\text { horizontal, } \\
\text { processos de } \\
\text { construção de } \\
\text { conhecimento }\end{array}$ & $\begin{array}{l}\text { Aprendizagem } \\
\text { organizacional, } \\
\text { reuso de } \\
\text { conhecimento, } \\
\text { renovação e } \\
\text { recombinação }\end{array}$ & $\begin{array}{c}\text { Duplicação de } \\
\text { recursos e } \\
\text { processos, } \\
\text { boundary spanning, } \\
\text { transferência de } \\
\text { conhecimento }\end{array}$ \\
\hline $\begin{array}{l}\text { Papel da } \\
\text { Gestão }\end{array}$ & $\begin{array}{l}\text { Encorajar cultura } \\
\text { de experimentação } \\
\text { e de inovação }\end{array}$ & $\begin{array}{c}\text { Reconhecer fontes } \\
\text { de conhecimento e } \\
\text { facilitar } \\
\text { transferência } \\
\text { interna (entre áreas) }\end{array}$ & $\begin{array}{l}\text { Analisar o ambiente } \\
\text { para oportunidades } \\
\text { de usar recursos } \\
\text { existentes em novas } \\
\text { combinações }\end{array}$ & $\begin{array}{c}\text { Pacotes de } \\
\text { conhecimento } \\
\text { dentro da empresa } \\
\text { para maximizar a } \\
\text { exploração de valor }\end{array}$ \\
\hline $\begin{array}{c}\text { Impacto na } \\
\text { Empresa }\end{array}$ & $\begin{array}{l}\text { Combinação de } \\
\text { recursos internos } \\
\text { para criar novo } \\
\text { conhecimento }\end{array}$ & $\begin{array}{c}\text { Permite à empresa } \\
\text { potencializar e } \\
\text { disponibilizar } \\
\text { conhecimento } \\
\text { original }\end{array}$ & $\begin{array}{l}\text { Permite à empresa } \\
\text { produzir novos } \\
\text { pacotes e únicos de } \\
\text { recursos }\end{array}$ & $\begin{array}{l}\text { Permite à empresa } \\
\text { replicar o sucesso } \\
\text { em diferentes } \\
\text { ambientes } \\
\text { organizacionais }\end{array}$ \\
\hline Benefícios & $\begin{array}{l}\text { Novo conhecimento } \\
\text { é apropriado } \\
\text { somente pela } \\
\text { empresa }\end{array}$ & $\begin{array}{c}\text { Utilização de } \\
\text { recursos existente } \\
\text { para gerar ganhos } \\
\text { econômicos e novas } \\
\text { configurações }\end{array}$ & $\begin{array}{c}\text { Uso de } \\
\text { componentes } \\
\text { conhecidos } \\
\text { decresce a incerteza } \\
\text { na inovação }\end{array}$ & $\begin{array}{c}\text { Crescimento } \\
\text { organizacional } \\
\text { baseado em } \\
\text { redistribuição } \\
\text { de conhecimento }\end{array}$ \\
\hline \multirow{2}{*}{ Tipos } & \multicolumn{4}{|c|}{ Foco Externo } \\
\hline & Desenvolvimento & Assimilação & Síntese & Imitação \\
\hline Dimensões & $\begin{array}{l}\text { Exploração } \\
\text { Combinativa }\end{array}$ & $\begin{array}{c}\text { Exploração } \\
\text { Absortiva }\end{array}$ & $\begin{array}{c}\text { Exploração } \\
\text { Combinativa }\end{array}$ & $\begin{array}{c}\text { Exploração } \\
\text { Absortiva }\end{array}$ \\
\hline Proposta & $\begin{array}{c}\text { Gerar } \\
\text { conhecimento fora } \\
\text { da empresa por } \\
\text { recombinação com } \\
\text { parceiro externo }\end{array}$ & $\begin{array}{c}\text { Busca por } \\
\text { informação fora da } \\
\text { empresa para } \\
\text { absorção e } \\
\text { aplicação }\end{array}$ & $\begin{array}{c}\text { Combina e } \\
\text { redistribui } \\
\text { conhecimento } \\
\text { existente da } \\
\text { empresa e parceiros } \\
\text { para criar vantagem } \\
\text { competitiva } \\
\end{array}$ & $\begin{array}{c}\text { Reconhecer e } \\
\text { duplicar } \\
\text { conhecimento } \\
\text { existente de outras } \\
\text { empresas }\end{array}$ \\
\hline Mecanismos & $\begin{array}{l}\text { Joint ventures, } \\
\text { acordos e criação } \\
\text { colaborativa de } \\
\text { conhecimento }\end{array}$ & $\begin{array}{l}\text { Aquisições, redes } \\
\text { de colaboração e } \\
\text { busca conjunta de } \\
\text { conhecimento }\end{array}$ & $\begin{array}{c}\text { Produção conjunta } \\
\text { e acordos de } \\
\text { marketing e } \\
\text { desenvolvimentos e } \\
\text { aplicações } \\
\text { conjuntas }\end{array}$ & $\begin{array}{c}\text { Acordos de } \\
\text { licenciamento e } \\
\text { engenharia reversa }\end{array}$ \\
\hline $\begin{array}{l}\text { Papel da } \\
\text { Gestão }\end{array}$ & $\begin{array}{c}\text { Desenvolver } \\
\text { alianças para } \\
\text { maximizar o valor } \\
\text { do conhecimento }\end{array}$ & $\begin{array}{c}\text { Buscar e } \\
\text { internalizar novo } \\
\text { conhecimento via } \\
\text { parcerias }\end{array}$ & $\begin{array}{c}\text { Adquirir } \\
\text { conhecimentos } \\
\text { externos e } \\
\text { coordenar recursos }\end{array}$ & $\begin{array}{c}\text { Identificar } \\
\text { oportunidades de } \\
\text { aprender dos } \\
\text { parceiros }\end{array}$ \\
\hline
\end{tabular}




\begin{tabular}{|c|c|c|c|c|}
\hline & $\begin{array}{c}\text { trocado e/ou } \\
\text { combinado }\end{array}$ & $\begin{array}{c}\text { internos em novas } \\
\text { combinações }\end{array}$ & voluntariamente \\
\hline $\begin{array}{c}\text { Impacto na } \\
\text { Empresa }\end{array}$ & $\begin{array}{c}\text { Permite à empresa } \\
\text { gerar novos } \\
\text { conhecimentos } \\
\text { com um parceiro }\end{array}$ & $\begin{array}{c}\text { Permite o } \\
\text { entendimento das } \\
\text { mudanças no } \\
\text { ambiente externo } \\
\text { e habilidades para } \\
\text { reação futura }\end{array}$ & $\begin{array}{c}\text { Permite à empresa } \\
\text { explorar o } \\
\text { conhecimento do } \\
\text { parceiro e } \\
\text { identificar } \\
\text { oportunidades de } \\
\text { aprendizado }\end{array}$ & $\begin{array}{c}\text { Permite } \\
\text { aprendizagem das } \\
\text { empresas mais } \\
\text { atrasadas e reduz a } \\
\text { dominância na } \\
\text { indústria (setor) }\end{array}$ \\
\hline Benefícios & $\begin{array}{c}\text { Aprendizado mútuo } \\
\text { resulta em novo } \\
\text { conhecimento para } \\
\text { as empresas } \\
\text { parceiras }\end{array}$ & $\begin{array}{c}\text { Crescimento da } \\
\text { empresa por } \\
\text { aquisição ou sua } \\
\text { inclusão em redes }\end{array}$ & $\begin{array}{c}\text { Alavancagem de } \\
\text { recursos dos } \\
\text { parceiros para } \\
\text { melhorar novas } \\
\text { configurações }\end{array}$ & $\begin{array}{c}\text { Recuperação ou } \\
\text { ganho de market } \\
\text { share ultrapassando } \\
\text { a dependência de } \\
\text { empresas pioneiras }\end{array}$ \\
\hline
\end{tabular}

Quadro 2: Os oito tipos de Capacidades Dinâmicas

Fonte: Adaptado de Denford (2013).

\subsection{A Relação entre as Capacidades Dinâmicas e Inovação}

O que se pode observar pela definição dos autores identificados por Denford (2013), é que as CD não são um fim em si mesmo, mas um meio para a empresa alcançar uma vantagem competitiva sustentável em ambientes turbulentos. Neste caso, a proposta deste estudo está em identificar a relação entre as $\mathrm{CD}$ e a inovação, enquanto resultado (desempenho). Como a proposta é estabelecer um framework de referência, o primeiro mapeamento não delimita o tipo de inovação, uma vez que a proposta não é estabelecer um modelo causal entre determinado tipo de CD e determinado tipo de inovação. $\mathrm{O}$ aspecto essencial nesta primeira discussão é entender que as CD contribuem para as Inovações de Produto, Processo, Organizacional, Mercado. Consoante a esta afirmação, Lee e Kelley (2008) evidenciam que as CD são um componente necessário para o processo de inovação, uma vez que este apresenta algum grau de mudança e de incerteza, e exige, portanto, que a empresa atue sobre suas competências internas e externas. Portanto, seja inovação de produto, processo, organizacional ou mercado, está se referindo a um processo de mudança, no qual as CD possuem seu papel.

Teece (2014) assume que as CD permitem a empresa gerar lucros superiores possibilitando o desenvolvimento e produção de produtos e serviços diferenciados que atingem novos mercados. Neste sentido, há essencialmente uma forte relação entre as CD e Inovação, na medida em que elas possibilitam que a organização integre, construa e reconfigure recursos internos e externos para manter liderança em ambientes turbulentos.

Lee e Kelley (2008) argumentam ainda, que a relação entre as CD e a inovação reside principalmente nos seguintes aspectos: (i) a inovação requer busca de novas informações além do conhecimento existente, muitas vezes em áreas não associadas às operações correntes da empresa

Revista de Administração e Inovação, São Paulo, v.12, n.1, p.271-302, jan./mar. 2015. 
(Nelson \& Winter, 1982; March, 1991); (ii) a inovação é um processo com algum nível de incerteza, o que produz poucos elementos previsíveis e repetidos (Nelson \& Winter, 1982); e (iii) a inovação envolve exploração, a partir de experimentação e de novas alternativas e requer variação e diversidade (March, 1991; Camisón \& Monfort-Mir, 2012). Para as diferentes tipologias de inovação (produto, processo, organizacional e mercado), estes aspectos podem ser observados.

Por conseguinte, a inovação demanda a criação de conhecimento em situações específicas, apresentando alta variabilidade sobre as atividades ou tarefas, resolução de problemas específicos ( $a d$ hoc), iteração e resultados imprevisíveis (Lee \& Kelley, 2008), e é neste contexto que as CD atuam a partir da habilidade da empresa em integrar, construir e reconfigurar competências internas e externas.

Sendo assim, Brühl, Horch e Osann (2010) afirmam que se o foco principal das CD é coordenar diferentes processos nas empresas, e sendo a inovação também um processo, isto implica na relação entre estes dois conceitos. De acordo com os autores, a inovação como um processo envolve mobilização e compartilhamento de conhecimento e, portanto, a relação entre a inovação, entendida enquanto resultado, e os processos operacionais, fundamentados nas CDBC. Para Branzei e Vertinsky (2006), a relação entre as CD e o desempenho ou o sucesso na inovação de produtos pode ser descrita a partir de dimensões, conforme apresentado na Figura 1.

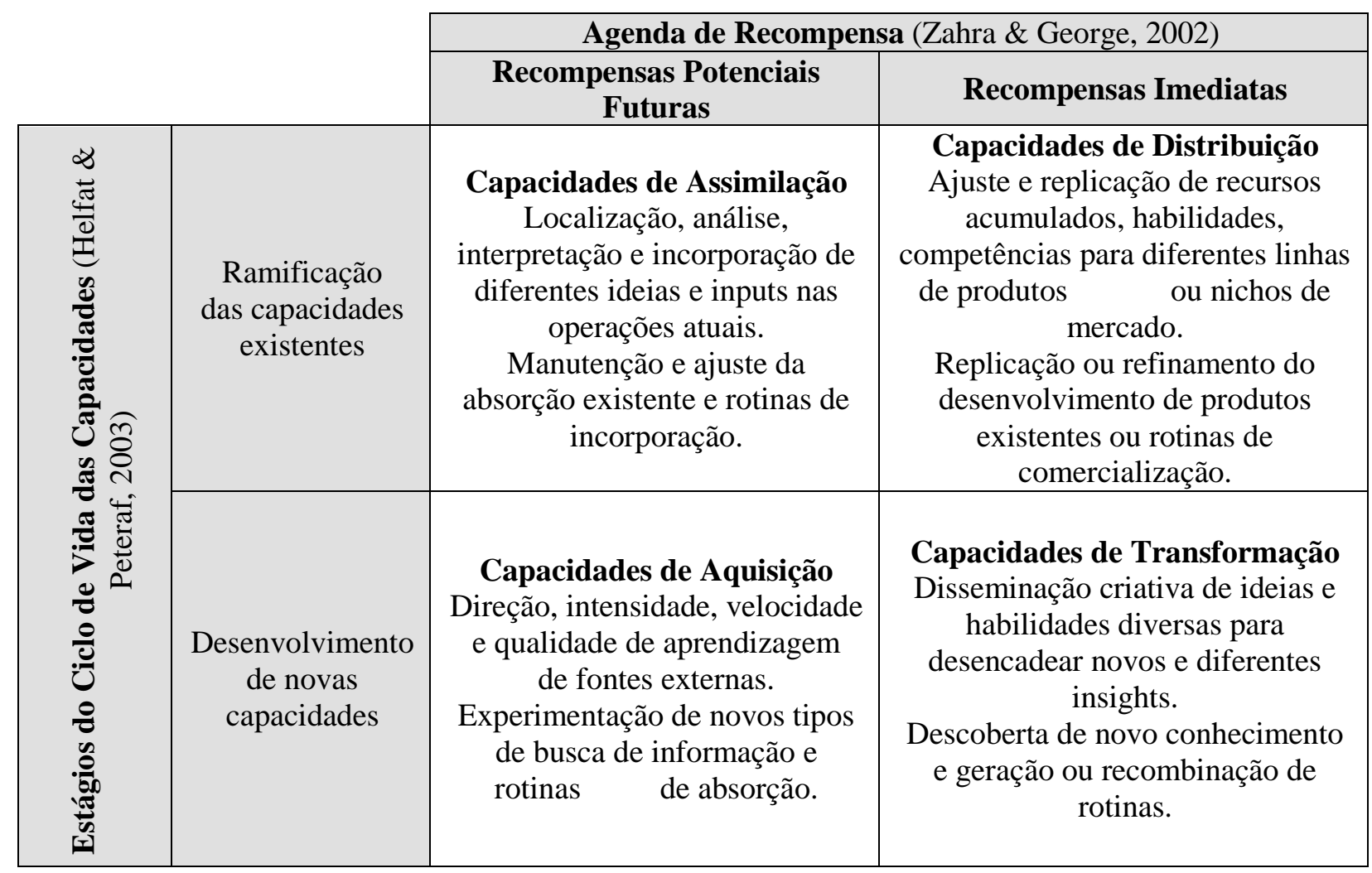

Figura 1: Relação entre capacidades, recompensas e inovação

Fonte: Adaptado de Branzei e Vertinsky (2006). 
É pertinente reforçar a argumentação de que a relação entre as CD e a Inovação não é baseada apenas em proposições teóricas, consistentes do ponto de vista lógico, mas também em evidências empíricas. Makkonen, Pohjola, Olkkonen e Koponen (2013) avaliaram a influência das CD na mudança organizacional e no desempenho de inovação de produto em 452 empresas finlandesas de diferentes setores. Os autores identificaram uma relação estatisticamente significativa do efeito entre as CD (operacionalizado por criação, integração, reconfiguração, replicação e assimilação) e o desempenho de inovação (operacionalizado pela medida de inovação de produto, analisando o share de novos produtos sobre o percentual do total de vendas das empresas analisadas). Zheng, Zhang, Wu e Du (2011) também encontraram relações positivas entre as CDBC e inovação, em seu estudo em empresas chinesas do setor eletroeletrônico. No caso desta pesquisa, as CDBC foram analisadas da perspectiva da a Capacidade de Aquisição de Conhecimento, Capacidade de Transformação de Conhecimento e Capacidade de Combinação de Conhecimento, na sua relação com a inovação de produto, apresentando efeitos significativos.

Contudo, ainda que haja um efeito indireto e estatisticamente significativo entre as CD e o Desempenho de Inovação no estudo de Makkonen et al. (2013), a relação entre CD e desempenho de inovação é mediada pela mudança organizacional, sendo que os efeitos diretos são maiores. Estes resultados reforçam a proposição de Zahra, Sapienza e Davidsson (2006) de que as CD agem sobre as capacidades operacionais, mudando-as e reconfigurando-as. O trabalho de Makkonen, Pohjola, Olkkonen e Koponen (2013) é importante no sentido de que valida (o estudo descreve a análise fatorial realizada, os Alphas de Cronbach, a validade convergente e a validade discriminante dos fatores ou dimensões) uma escala multidimensional das $\mathrm{CD}$, que consiste nas seguintes dimensões e indicadores apresentados no Quadro 4.

\begin{tabular}{|c|c|}
\hline Dimensões & Itens \\
\hline \multirow{2}{*}{$\begin{array}{c}\text { Perceber e } \\
\text { Aproveitar } \\
\text { Oportunidades }\end{array}$} & $\begin{array}{l}\text { Buscamos sistematicamente por novos modelos de negócio pela observação de } \\
\text { processos no ambiente [mercado]. }\end{array}$ \\
\hline & $\begin{array}{l}\text { Aproximamos sistematicamente as pessoas criativas e as com conhecimento de } \\
\text { dentro da empresa para identificar novas oportunidades de negócio. }\end{array}$ \\
\hline \multirow{2}{*}{$\begin{array}{l}\text { (Sensing } \\
\text { and Seizing) }\end{array}$} & $\begin{array}{l}\text { Aproximamo-nos sistematicamente das pessoas criativas e das com conhecimento } \\
\text { de fora da empresa para ajudar a identificar novas oportunidades de negócio. }\end{array}$ \\
\hline & $\begin{array}{l}\text { Nossa empresa sistematicamente transfere recursos para o desenvolvimento de } \\
\text { novas atividades de negócio. }\end{array}$ \\
\hline \multirow{4}{*}{$\begin{array}{l}\text { Criação de } \\
\text { Conhecimento }\end{array}$} & $\begin{array}{c}\text { Nós buscamos aumentar os investimentos em P\&D - Pesquisa \& } \\
\text { Desenvolvimento. }\end{array}$ \\
\hline & Nossa empresa tem planos específicos para as atividades de P\&D. \\
\hline & Nossa gestão promove processos de P\&D. \\
\hline & Temos rotinas de P\&D desenvolvidas em nossa empresa. \\
\hline Integração & $\begin{array}{c}\text { Nossa empresa se utiliza de redes (pessoas, empresas, etc.) como recursos de } \\
\text { conhecimento. }\end{array}$ \\
\hline
\end{tabular}




\begin{tabular}{|c|c|}
\hline & Nossa empresa explora as redes pessoais [relacionamentos] dos gestores. \\
\hline & $\begin{array}{c}\text { As redes de contato dos funcionários são importantes fontes de informação da } \\
\text { empresa. }\end{array}$ \\
\hline & Nossa empresa utiliza redes para influenciar pessoas no ambiente externo. \\
\hline & $\begin{array}{l}\text { Temos rotinas desenvolvidas para permitir uma participação ativa dos funcionários } \\
\text { na geração de ideias para novos produtos e/ou serviços. }\end{array}$ \\
\hline Reconfiguração & $\begin{array}{c}\text { Temos rotinas desenvolvidas para permitir uma participação ativa dos funcionários } \\
\text { na geração de ideias para novos processos de produção ou procedimentos } \\
\text { organizacionais. }\end{array}$ \\
\hline & Nossa empresa tem rotinas para sistematizar as experiências dos funcionários. \\
\hline & $\begin{array}{l}\text { Nossos funcionários têm mais vontade de adotar novas maneiras de trabalhar do } \\
\text { que os de nossos concorrentes (este item não permaneceu no modelo final dos } \\
\text { autores). }\end{array}$ \\
\hline Alavancagem & $\begin{array}{l}\text { Nossos funcionários têm mais espaço para explorar novas oportunidades, contanto } \\
\text { que não afete suas atividades atuais. }\end{array}$ \\
\hline & $\begin{array}{c}\text { A empresa encoraja fortemente os funcionários e gestores para promover novas } \\
\text { visões, metas e ideias. }\end{array}$ \\
\hline & $\begin{array}{l}\text { A empresa enfatiza a necessidade de aumentar o nível de competência entre os } \\
\text { funcionários. }\end{array}$ \\
\hline Aprendizagem & A empresa aloca recursos para aumentar a competência dos funcionários. \\
\hline & $\begin{array}{l}\text { A empresa encoraja fortemente os funcionários a aprender a partir de suas } \\
\text { experiências. }\end{array}$ \\
\hline
\end{tabular}

Quadro 4: Dimensões e indicadores das Capacidades Dinâmicas

Fonte: Makkonen, Pohjola, Olkkonen e Koponen (2013).

A partir destas sustentações teóricas este estudo buscou aprofundar a análise entre as diferentes abordagens das CD, conforme identificadas na literatura, e a Inovação, cuja relação com as CD está em teoria bem estabelecida.

\section{MÉTODO DE PESQUISA}

Considerando o objetivo deste estudo, que foi o de identificar as relações entre as diferentes abordagens de CD e o Desempenho de Inovação de Produto, considera-se que a abordagem de pesquisa mais apropriada era a de natureza qualitativo-exploratória (Remler \& Van Ryzin, 2011; Scott \& Garner, 2013), utilizando-se como método central de pesquisa a análise de conteúdo (Gibbs, 2008; Bardin, 2009; Hennink, Hutter, \& Bailey, 2011; Schreier, 2012), a partir de dados e informações coletados de artigos publicados sobre o tema. 


\subsection{Delimitação do Escopo da Pesquisa e o Processo de Coleta de Dados}

A primeira etapa da pesquisa consistiu na definição do escopo para a coleta de dados, tendo em vista a busca por artigos que abrangessem as CD relacionadas com a inovação de produto, independentemente do método de pesquisa utilizado. Em essência, a estratégia de pesquisa buscou consultar o termo "capacidades dinâmicas" no título, no abstract (resumo) ou nas key words (palavraschave), relacionado com "inovação", termo inserido de forma genérica, não delimitando-o pelo tipo no primeiro momento. Quando necessário, foram aplicados filtros para delimitar artigos apenas da área de gestão.

A coleta de dados (busca pelos artigos publicados) foi realizada utilizando as seguintes bases de pesquisa: Science Direct, Web of Knowledge, Web of Science, Sage, Wiley, Ebsco, Proquest, Emerald e Scopus, as quais possibilitaram o acesso a Journals de alto fator de impacto. Como operadores booleanos de pesquisa, é apresentada, no Quadro 5, a base consultada, a forma de consulta e a quantidade de artigos cujo download foi realizado.

\begin{tabular}{|c|c|c|}
\hline Bases & Operadores Booleanos Utilizados & $\begin{array}{c}\text { Artigos } \\
\text { Coletados }\end{array}$ \\
\hline Ebsco & $\begin{array}{l}\text { Title or Abstract contains: "Dynamic } \\
\text { capabilities" and innovation }\end{array}$ & 01 \\
\hline Emerald & $\begin{array}{c}\text { Content = Journals, ("dynamic capabilities" in all except full } \\
\text { text) and ("innovation" in all except full text), inc. EarlyCite } \\
\text { articles, inc. Backfiles content }\end{array}$ & 20 \\
\hline Proquest & $\begin{array}{c}\text { Proquest: all (innovation) AND all((“dynamic capability" } \\
\text { OR “dynamic capabilities”)) }\end{array}$ & 61 \\
\hline Sage & $\begin{array}{c}\text { Dynamic Capability + Innovation } \\
\text { "dynamic capabilities" and innovation in all fields }\end{array}$ & 02 \\
\hline $\begin{array}{c}\text { Science } \\
\text { Direct }\end{array}$ & $\begin{array}{c}\text { Dynamic capabilities + innovation (abstract tittle keywords). } \\
\text { All years }\end{array}$ & 56 \\
\hline Scopus & $\begin{array}{l}\text { (TITLE-ABS-KEY(dynamic capabilities) AND TITLE-ABS- } \\
\text { KEY(innovation)) Limit to article, article in press } \\
\text { Business, Management, Social Science, Economics }\end{array}$ & 94 \\
\hline $\begin{array}{l}\text { Web of } \\
\text { Knowledge }\end{array}$ & $\begin{array}{c}\text { All Databases } \\
\text { Topic=(“dynamic capabilities") AND Topic=(innovation) } \\
\text { Refined by: Research Areas=( BUSINESS ECONOMICS OR } \\
\text { OPERATIONS RESEARCH MANAGEMENT SCIENCE } \\
\text { OR SOCIAL SCIENCES OTHER TOPICS ) AND Document } \\
\begin{array}{c}\text { Types }=\quad \text { (ARTICLE ) Timespan=All years. Search } \\
\text { language=Auto }\end{array} \\
\text { Title=("dynamic capabilities") AND Title=(innovation) }\end{array}$ & 23 \\
\hline $\begin{array}{l}\text { Web of } \\
\text { Science }\end{array}$ & $\begin{array}{l}\text { Your query: (TITLE-ABS-KEY(“dynamic capabilities”) } \\
\text { AND TITLE-ABS-KEY(innovation)) AND (LIMIT- } \\
\text { TO(DOCTYPE, “ar”) OR LIMIT-TO(DOCTYPE, “ip”)) } \\
\text { AND (LIMIT-TO(SUBJAREA, "BUSI") OR LIMIT- } \\
\text { TO(SUBJAREA, "SOCI”) OR LIMIT-TO(SUBJAREA, }\end{array}$ & 54 \\
\hline
\end{tabular}

Revista de Administração e Inovação, São Paulo, v.12, n.1, p.271-302, jan./mar. 2015. 


\begin{tabular}{|c|c|c|}
\hline & "ECON")) & \\
\hline \multirow{2}{*}{ Wiley } & "Dynamic capability" in Article Titles AND innovation in \\
Article Titles & 08 \\
\hline \multicolumn{2}{|c|}{ Total de Artigos Coletados } & $\mathbf{3 1 9}$ \\
\hline
\end{tabular}

Quadro 5: Forma de consulta nas bases de dados e artigos coletados

Cabe ressaltar que houve artigos que não foram coletados em função do Journal estar indisponível para as bases onde se realizaram a consulta. Obteve-se, portanto, um total de 319 artigos coletados. No entanto, como diferentes bases podem levar ao mesmo Journal, os artigos foram cruzados para eliminar duplicações, resultando em uma amostra final de 233 documentos (artigos) (73\%) para análise.

\subsection{Categorias de Análise e Codificação e Categorização dos Dados}

A codificação e a categorização dos artigos foram desenvolvidas com o auxílio do software MAXQDA 11, apenas para fins de organização dos dados e filtro dos artigos a serem analisados em última instância.

Como categorias e códigos a priori do estudo, definiram-se aspectos a serem analisados de forma a estabelecer a relação entre CD e Inovação de Produto, em especial, com base nas dimensões definidas por Denford (2013). De acordo com o Quadro 6, são descritas as categorias de análise, os códigos associados e o método de codificação utilizado.

\begin{tabular}{|c|c|c|}
\hline Categorias & Códigos & Método de Codificação \\
\hline Ano & $(1991 \ldots 2013)$ & $\begin{array}{l}\text { Identificação do ano na primeira } \\
\text { página do artigo. }\end{array}$ \\
\hline Tipos de Estudo & Estudo de caso, survey e outros & $\begin{array}{c}\text { Utilização da busca léxica pelos termos } \\
\text { nos artigos. Identificação de se o termo } \\
\text { se referia ao método do próprio artigo ou } \\
\text { a outro artigo citado. Aplicado quando } \\
\text { denominava o método principal do } \\
\text { estudo. }\end{array}$ \\
\hline Amostra & Gerado a posteriori & $\begin{array}{l}\text { A partir do filtro dos estudos survey, } \\
\text { identificado no resumo ou na seção de } \\
\text { metodologia, com a amostra analisada. }\end{array}$ \\
\hline Tipo de Inovação & $\begin{array}{l}\text { Gerado a posteriori. Categorias } \\
\text { identificadas: } \\
\text { Produto: Inovação de Produto, } \\
\text { Inovação Tecnológica, Vantagem } \\
\text { Competitiva do Produto, Inovação } \\
\text { Radical. } \\
\text { Processo: Inovação de Processo. } \\
\text { Inovatividade: Capacidade de }\end{array}$ & Leitura do texto. \\
\hline
\end{tabular}




\begin{tabular}{|c|c|c|}
\hline & $\begin{array}{l}\text { Inovação, Velocidade de Inovação, } \\
\text { Persistência de Inovação. } \\
\text { Organizacional: Inovação na } \\
\text { Empresa, Inovação Organizacional, } \\
\text { Estratégia de Inovação. }\end{array}$ & \\
\hline $\begin{array}{l}\text { Abordagem das } \\
\text { CD Utilizada }\end{array}$ & $\begin{array}{l}\text { Teece, Pisano e Shuen (1997), } \\
\text { Eisenhardt e Martin (2000), Helfat e } \\
\text { Peteraf (2003), Verona e Ravasi } \\
\text { (2003), Zahra, Sapienza e Davidsson } \\
\text { (2006), Rothaermel e Alexandre } \\
\text { (2009) e Cheng e Chen (2013) }\end{array}$ & $\begin{array}{c}\text { Utilização da busca léxica pelos termos } \\
\text { nos artigos. Apenas uma codificação por } \\
\text { autor no artigo quando citado no corpo } \\
\text { do texto. }\end{array}$ \\
\hline $\begin{array}{l}\text { Operacionalização } \\
\text { do Construto CD }\end{array}$ & $\begin{array}{l}\text { Criação, Integração, Identificação, } \\
\text { Reconfiguração, Replicação, } \\
\text { Desenvolvimento, Assimilação, } \\
\text { Síntese, Imitação (Denford, 2013) }\end{array}$ & Leitura do texto. \\
\hline País & Gerado a posteriori & Leitura do texto. \\
\hline
\end{tabular}

Quadro 6: Categorias de análise e codificação dos dados

\section{ANÁLISE E DISCUSSÃO DOS RESULTADOS}

Na Tabela 1, observa-se a distribuição dos artigos coletados, por ano e por método de pesquisa implementado. Salienta-se que dos 233 trabalhos, 27\% deles são declarados como sendo estudos de caso, $24 \%$ estudos do tipo survey e $48 \%$ consistem em outros tipos de estudo (teóricos ou de outra abordagem qualitativa). Dessa forma, para analisar a relação entre as CD e a Inovação, foi utilizado o recorte de apenas considerar os artigos que foram desenvolvidos com método de pesquisa do tipo survey, uma vez que esta abordagem apresenta as relações estatísticas testadas de forma empírica, não se tratando apenas de proposições teóricas ou relações e generalizações analíticas de estudos de caso.

Portanto, a amostra final analisada se restringiu a 56 trabalhos, sendo a maior parte deles publicados entre 2011 e 2012 e 2013, o que demonstra a emergência do método dentro deste tema.

Tabela 1: Artigos publicados sobre Capacidades Dinâmicas e Inovação

\begin{tabular}{|c|c|c|c|c|}
\hline Período (Anos) & Outros Estudos & Estudos de Caso & Survey & Total Geral \\
\hline 1991 & 1 & - & - & 1 \\
\hline 1998 & - & 1 & - & 1 \\
\hline 2001 & 2 & - & - & 2 \\
\hline 2002 & 8 & - & 2 & 10 \\
\hline 2003 & 6 & - & - & 6 \\
\hline 2004 & 6 & 2 & - & 8 \\
\hline 2005 & 4 & - & - & 4 \\
\hline 2006 & 20 & 2 & 4 & 26 \\
\hline 2007 & 10 & 1 & 2 & 13 \\
\hline 2008 & 14 & 8 & 2 & 24 \\
\hline
\end{tabular}




\begin{tabular}{|c|c|c|c|c|}
\hline 2009 & 11 & 13 & 3 & 27 \\
\hline 2010 & 7 & 1 & 4 & 12 \\
\hline 2011 & 11 & 15 & 10 & 36 \\
\hline 2012 & 12 & 8 & 17 & 37 \\
\hline 2013 & - & 14 & 12 & 26 \\
\hline Total Geral & $\mathbf{1 1 2}$ & $\mathbf{6 5}$ & $\mathbf{5 6}$ & $\mathbf{2 3 3}$ \\
\hline
\end{tabular}

Fonte: Elaborada pelos autores com base nos dados da pesquisa.

Destes 56 trabalhos, após uma leitura dos artigos, aqueles que não apresentaram de forma clara e definida os construtos e indicadores associados às CD e à Inovação de Produto foram excluídos da análise. Da mesma maneira, pesquisas em que a inovação não fosse variável dependente também não foram consideradas. Um exemplo é o estudo de Hoffman, Theyel e Wood (2012), que analisaram em 294 pequenas empresas, de sete setores industriais dos Estados Unidos, com as dimensões de adoção tecnológica (nível de adoção de tecnologia avançada) e colaboração (com clientes e fornecedores) como proxies para as $\mathrm{CD}$, e a habilidade de inovação em relação ao desenvolvimento de produtos.

Entretanto, estas variáveis, no modelo de regressão, eram independentes em relação à habilidade de implementação de práticas ambientais, enquanto variável dependente. O estudo acabou se enquadrando aos critérios iniciais do recorte utilizado por se tratar de uma survey com os termos CD e Inovação. Mas, a partir da análise de conteúdo, observou-se que não se configurava como um estudo adequado para a próxima etapa de análise, uma vez que o objetivo era o de analisar a influência das CD (variável independente) no Desempenho de Inovação (variável dependente).

Nesta etapa, os artigos foram organizados em termos de "Tipo de Estudo", "Amostra", “Capacidades Dinâmicas (CD)", "Tipo de Inovação" e "Resultado", sendo codificados a partir da leitura do resumo e do texto, integralmente, conforme descrito na seção do método. Desta seleção, verificou-se que 25 estudos (vide Apêndice) se caracterizaram como sendo pesquisas do tipo survey e que apresentavam a relação entre $\mathrm{CD}$ e Inovação, contemplando construtos e indicadores bem delimitados, os quais estão relacionados no Apêndice, ao final do trabalho.

\subsection{Convergências e Divergências Encontradas}

O que se identifica a partir dos estudos, em um primeiro momento, é a impossibilidade de geração de uma meta-análise em termos dos efeitos agregados das CD na Inovação ou no Desempenho de Inovação, tal como realizado em estudos de construtos consolidados, tais como a Orientação para o Mercado (Kirca, Jayachandran, \& Bearden, 2005; Shoham, Rose, \& Kropp, 2005; Canoa, Carrilat, \& Jaramillo, 2004), consistindo em marcos importantes no desenvolvimento teórico de uma área.

Revista de Administração e Inovação, São Paulo, v.12, n.1, p.271-302, jan./mar. 2015. 
Isso se dá não somente em função do critério quantidade de artigos, mas principalmente em termos da qualidade no que se refere à delimitação e à utilização dos mesmos construtos e medidas, seja para CD, seja para Inovação. Nestes 25 estudos foram identificados nove tipos/nomenclaturas diferentes de inovação, conforme exposto no Quadro 7, sendo que mesmo os que trataram a Inovação de Produto utilizaram indicadores diferentes para operacionalizar o construto.

No que se refere às $\mathrm{CD}$, a divergência de operacionalização é ainda maior, sendo que, foi desenvolvida uma síntese da ocorrência do tipo de CD (dimensões) nos estudos. Há estudos que utilizam três das capacidades das tipologias identificadas por Denford (2013) para compor o construto, enquanto outros utilizam um fenômeno específico que se caracteriza como $\mathrm{CD}$, como é o caso de Kohlbacher (2013), que analisou a melhoria contínua como CD e sua relação com a inovação.

Em termos de frequência da ocorrência das $\mathrm{CD}$, observou-se, por exemplo, que a $\mathrm{CD}$ de Integração foi utilizada em seis estudos, e também foi compreendida pela tipologia proposta por Denford (2013). Porém, a CD de Perceber e Aproveitar Oportunidades (Sensing and Seizing) foi analisada em cinco estudos, a qual não foi identificada na proposição de Denford (2013). Já a tipologia de Replicação, conforme proposta por este autor, não foi identificada em nenhum dos estudos, a não ser que se interprete a mesma a partir da definição de Transformação e Conversão.

Tais resultados indicam a falta de homogeneidade ou de convergência na definição do construto (CD), e trazem implicações tanto teóricas quanto em termos das próprias contribuições gerenciais que poderiam advir da relação entre os estudos, principalmente no que tange à variável dependente (Inovação), a qual foi operacionalizada de maneiras distintas. É paradoxal que, em 16 anos de existência do conceito de $\mathrm{CD}$, que é um dos mais pesquisados na área de Estratégia, observe-se tamanha divergência na sua operacionalização nos estudos do tipo survey, evidenciada pelos dados deste estudo, que a priori selecionou as pesquisas que apresentaram delimitação do construto e indicadores de mensuração.

\begin{tabular}{|c|c|c|}
\hline $\begin{array}{c}\text { Tipos de Capacidades } \\
\text { Dinâmicas (Denford, } \\
\text { 2013) }\end{array}$ & $\begin{array}{l}\text { Capacidades Dinâmicas } \\
\text { (Quantidades de Estudos) }\end{array}$ & $\begin{array}{c}\text { Tipos de Inovação } \\
\text { (Quantidades de Estudos) }\end{array}$ \\
\hline Criação & Criação (1) e Geração (1) & \multirow{8}{*}{$\begin{array}{c}\text { Desempenho de Inovação de } \\
\text { Produto (10), Desempenho de } \\
\text { Inovação de Processo (4), } \\
\text { Inovação Tecnológica (2), } \\
\text { Capacidade de Inovação (1), } \\
\text { Velocidade de Inovação (1), } \\
\text { Persistência de Inovação (1), } \\
\text { Vantagem Competitiva do } \\
\text { Produto (1), Inovação na } \\
\text { Empresa / Inovação } \\
\text { Organizacional (2), Estratégia de } \\
\text { Inovação (1) e Inovação Radical }\end{array}$} \\
\hline Integração & Integração (6) & \\
\hline Reconfiguração & $\begin{array}{c}\text { Reconfiguração / Recombinação } \\
\text { (3) } \\
\text { Combinação (2) } \\
\text { Transformação / Conversão (3) }\end{array}$ & \\
\hline Replicação & Não identificado & \\
\hline Desenvolvimento & Desenvolvimento (2) & \\
\hline Assimilação & $\begin{array}{c}\text { Assimilação (5) e Aprendizagem } \\
\text { (2) }\end{array}$ & \\
\hline Síntese & Não identificado & \\
\hline Imitação & Não identificado & \\
\hline
\end{tabular}

Revista de Administração e Inovação, São Paulo, v.12, n.1, p.271-302, jan./mar. 2015. 


\begin{tabular}{|c|c|c|}
\hline \multirow{4}{*}{$\begin{array}{l}\text { Termos não contemplados } \\
\text { na Tipologia de Denford } \\
\text { (2013) e considerados } \\
\text { nos estudos }\end{array}$} & $\begin{array}{c}\text { Perceber e Aproveitar } \\
\text { Oportunidades (Sensing e } \\
\text { Seizing) }(5)\end{array}$ & \multirow[t]{5}{*}{ (1) } \\
\hline & Aquisição (4) & \\
\hline & Aplicação (2) e Implantação (2) & \\
\hline & Alavancagem (1) & \\
\hline $\begin{array}{l}\text { Outros conceitos utilizados } \\
\text { como sendo CD }\end{array}$ & $\begin{array}{l}\text { Capacidades Tecnológicas (2), } \\
\text { Capacidades Exploratórias, } \\
\text { Busca Externa, Codificação e } \\
\text { Articulação do Conhecimento, } \\
\text { Adoção/Colaboração } \\
\text { Tecnológica, Melhoria Contínua, } \\
\text { Gestão de Portfólio de Projetos, } \\
\text { Fator GC, Gestão do } \\
\text { Relacionamento (1) }\end{array}$ & \\
\hline
\end{tabular}

\section{Quadro 7: Síntese das ocorrências de surveys sobre Capacidades Dinâmicas}

Contudo, ainda que as CD tenham sido medidas por diferentes indicadores (ou escalas), todas as pesquisas apresentaram uma relação estatística positiva entre as CD e a Inovação de Produto ou Inovatividade, o que estabelece e reafirma esta competência como estratégica para as empresas. No caso de Inovação de Produto, podem ser agrupados "Desempenho de Inovação de Produto, Inovação Tecnológica, Vantagem Competitiva do Produto, Inovação Radical”, resultando em 14 casos. Para a Inovatividade, podem ser agrupados "Capacidade de Inovação", "Velocidade de Inovação", "Persistência de Inovação", resultando em 5 casos. Dos artigos, 4 casos referem-se à inovação de processo e 3 de inovação organizacional. Para fins deste artigo, as 14 evidências serão utilizadas como para elucidar a relação entre as CDBC e a Inovação de Produto. Evidencia-se que o único estudo que apresentou uma relação diferente foi o de Cheng e Chen (2013), em que há um comportamento de uinvertido quando se trata de inovação radical.

Ainda que os resultados deste estudo sugiram a proposição de uma agenda de pesquisa que em futuras investigações haja uma uniformidade na seleção de CD a serem contempladas e do tipo de inovação pesquisado, de modo a possibilitar a construção de relações estatísticas entre estes estudos, é possível, com base nestes trabalhos empíricos, propor um modelo mais amplo atinente às $\mathrm{CD}$, que dê conta das suas principais dimensões, construído a partir da Tipologia de Denford (2013), as relações testadas de Makkonen, Pohjola, Olkkonen e Koponen (2013) e dimensões identificadas neste recorte de estudos que efetuaram uma análise estatística, tendo por base a identificação realizada no Quadro 7. Com a seleção destas três perspectivas, considera-se que se estabelece uma fronteira e amplitude de mapeamento, uma vez que o trabalho de Denford (2013) já resultou em esforço de síntese de 80 estudos, o trabalho de Makkonen et. al (2013) foi um estudo quantitativo publicado após, 
estabelecendo novas referências e os demais estudos survey analisados também agregaram contribuições.

Neste sentido, para facilitar a compreensão, no Quadro 8, é apresentado uma comparação da tipologia qualitativa de Denford (2013), da escala estatisticamente validada por Makkonen, Pohjola, Olkkonen e Koponen (2013), e das dimensões não contempladas por estes autores, mas que apresentaram relação estatística validada nos estudos surveys. Nota-se que há uma convergência parcial entre as capacidades utilizadas pelos autores. Com base nestas três perspectivas, uma quarta (dimensões do modelo proposto) é evidenciada, a qual servirá para a representação visual das relações, construída com critério descrito na próxima seção.

\begin{tabular}{|c|c|c|c|}
\hline $\begin{array}{c}\text { Makkonen, , Pohjola, Olkkonen } \\
\text { e Koponen (2013) }\end{array}$ & Denford (2013) & $\begin{array}{c}\text { Dimensões não } \\
\text { Contempladas e que } \\
\text { Apresentaram } \\
\text { Relação Estatística } \\
\text { nos Estudos } \\
\text { selecionados } \\
\end{array}$ & $\begin{array}{c}\text { Dimensões do } \\
\text { Modelo Proposto }\end{array}$ \\
\hline $\begin{array}{l}\text { Sensing e Seizing: a capacidade de } \\
\text { se posicionar favoravelmente no } \\
\text { ambiente e explorar novas } \\
\text { oportunidades }\end{array}$ & & & Sensing e Seizing \\
\hline $\begin{array}{l}\text { Criação de Conhecimento: } \\
\text { capacidade de continuamente criar e } \\
\text { absorver novo conhecimento, e } \\
\text { desenvolver novos produtos ou } \\
\text { processos, também conhecido como } \\
\text { capacidade absortiva }\end{array}$ & Criação & & $\begin{array}{c}\text { Criação de } \\
\text { Conhecimento }\end{array}$ \\
\hline $\begin{array}{l}\text { Integração: capacidade de adquirir } \\
\text { e integrar novo conhecimento por } \\
\text { meio de fontes externas como redes, } \\
\text { também se referindo a utilização do } \\
\text { capital social }\end{array}$ & Integração & & Integração \\
\hline $\begin{array}{l}\text { Reconfiguração: Capacidade de } \\
\text { continuamente e com propósito } \\
\text { reconfigurar a base de recursos } \\
\text { existentes, possibilitando a empresa } \\
\text { a transformar e explorar } \\
\text { conhecimento específico. }\end{array}$ & Reconfiguração & & Reconfiguração \\
\hline $\begin{array}{l}\text { Leveraging (aproveitamento): } \\
\text { capacidade de utilizar e implantar } \\
\text { um recurso existente em uma } \\
\text { situação nova, permitindo a empresa } \\
\text { a replicar uma capacidade } \\
\text { operacional em um novo mercado }\end{array}$ & & Implantação (2) & $\begin{array}{l}\text { Alavancagem e } \\
\text { Implantação }\end{array}$ \\
\hline $\begin{array}{l}\text { Aprendizado: capacidade que } \\
\text { permite a empresa adquirir, adotar, e } \\
\text { criar novas capacidades por meio } \\
\text { dos processos de aprendizado da } \\
\text { organização } \\
\end{array}$ & Assimilação & $\begin{array}{l}\text { Aquisiçãa (5) } \\
\text { Interpretação (1) }\end{array}$ & $\begin{array}{l}\text { Aquisição, } \\
\text { Assimilação e } \\
\text { Aprendizado }\end{array}$ \\
\hline
\end{tabular}




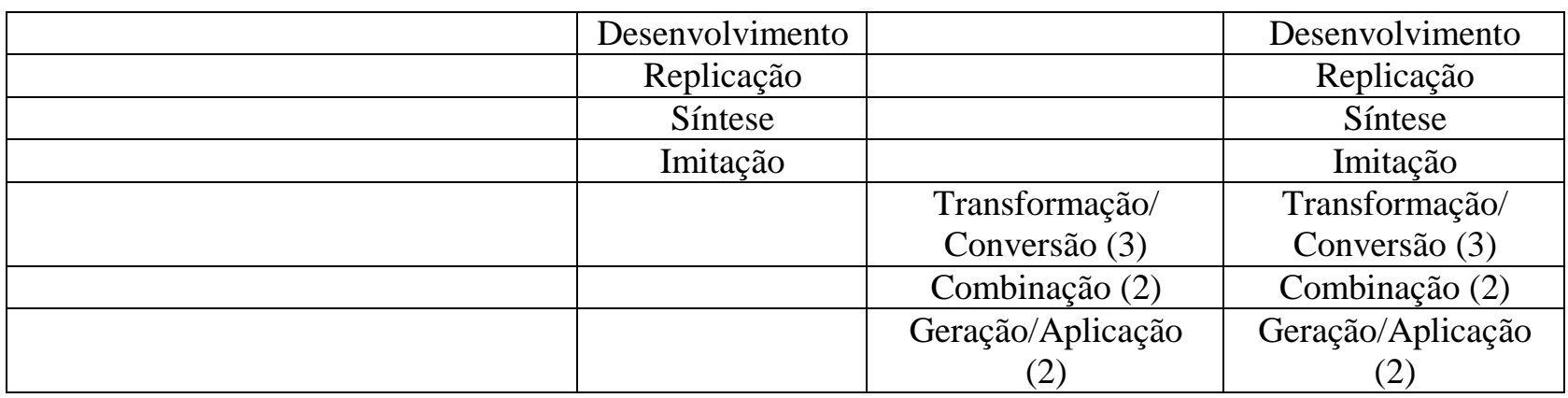

Quadro 8: Comparação entre os estudos

No caso da comparação entre os estudos, por exemplo, tanto Makkonen, Pohjola, Olkkonen e Koponen (2013) quanto Denford (2013) falam em criação de conhecimento e convergem nesta definição. Porém, enquanto para Makkonen, Pohjola, Olkkonen e Koponen (2013) a definição de Integração tem a ver com busca em redes externas (conforme observado nos seus indicadores), para Denford (2013), a integração é uma capacidade que tem a ver com o conhecimento interno da empresa. Ou seja, com a mesma denominação para tal CD, os autores estão se referindo a mecanismos diferentes, e essa problemática é levantada em relação a uma tipologia construída e publicada em um Journal de referência na área, propondo uma escala validada estatisticamente e que servirá de base para o desenvolvimento de novos estudos de pesquisadores interessados na área.

A partir desta leitura e de tais divergências, considera-se essencial que se estabeleça um framework de referência, construído a partir de estudos com relações estatisticamente testadas, e que se proponha a servir como um modelo unificado de CD para os diferentes tipos de inovação. Como forma de visualmente orientar o pesquisador e compreender este fenômeno complexo, o modelo unificado busca convergir as nomenclaturas utilizadas pelos autores, e agregando mais duas dimensões, aquilo que se refere à cultura organizacional (orientação) e aquilo que se refere à processo (fluxos). Com essa contribuição, pesquisas futuras sobre as relações entre distintas CDBC e tipos de inovação poderão ser melhor uniformizadas.

Outra reflexão relevante é que Denford (2013) descreve a CD da Imitação. Contudo, a imitação, para ocorrer, demanda uma aquisição de conhecimento (coleta), sua assimilação (interpretação) e seu aprendizado (internalização). Imitação não se refere a um processo, mas a uma orientação da empresa. A capacidade de imitação permite a ela integrar, construir e reconfigurar competências (imitando o concorrente), mas, para isso, precisa ter a capacidade de Aquisição, de Assimilação e de Aprendizado, caso contrário, não conseguirá exercer a capacidade de imitar.

$\mathrm{Na}$ tentativa de convergir e esclarecer tais dimensões, verifica-se que é insuficiente apenas uma comparação de categorias dada a complexidade das mesmas, mas sim é necessário num primeiro momento uma esquematização para fins de análise sistêmica das relações, tendo em vista o contexto. 
Neste sentido, o modelo unificado apresentado na Figura 2, apresentado mais adiante, emergiu a partir da interpretação do Quadro 8, na proposição de uma síntese das dimensões defendidas pelos autores.

\subsection{O Modelo Unificado das Capacidades Dinâmicas Baseadas em Conhecimento e Tipos de Inovação}

O elemento central do Modelo Unificado é o Conhecimento da Empresa, sobre o qual as CD atuam (Grant, 1996; Von Krogh, Nonaka, \& Aben, 2001; Zollo \& Winter, 2002) e é quem basicamente contribui para as CD. Para fins de discriminação das categorias, adotaram-se as dimensões de conhecimento novo e existente, e de dentro e fora da empresa (origem). É com base nestas relações que as CD se constroem, enquanto processo, conforme apresentado no Quadro 9, e respeitando as tipologias já mapeadas nos estudos supracitados. Por exemplo, a CD de criação é uma relação que ocorre dentro das fronteiras da organização (na perspectiva sistêmica), entre conhecimentos novos, provavelmente de áreas distintas da organização. Já por desenvolvimento entende-se que a relação entre um conhecimento novo da organização com um conhecimento novo externo.

\begin{tabular}{|c|c|c|c|c|c|}
\hline \multirow{2}{*}{\multicolumn{2}{|c|}{ Conhecimento }} & \multicolumn{2}{|c|}{ Interno } & \multicolumn{2}{|c|}{ Externo } \\
\hline & & \multirow{2}{*}{$\begin{array}{c}\text { Novo } \\
\text { Criação } \\
\text { Geração }\end{array}$} & \multirow[t]{2}{*}{ Existente } & \multirow{2}{*}{$\begin{array}{c}\text { Novo } \\
\text { Desenvolvimento }\end{array}$} & \multirow[t]{2}{*}{ Existente } \\
\hline \multirow{3}{*}{ Interno } & Novo & & & & \\
\hline & Existente & & $\begin{array}{c}\text { Recombinação } \\
\text { Reconfiguração } \\
\text { Combinação } \\
\text { Conversão } \\
\text { Transformação }\end{array}$ & & Integração \\
\hline & Inexistente & & & & Aquisição \\
\hline
\end{tabular}

Quadro 9: Relação entre as Capacidades Dinâmicas, tipo de conhecimento e origem

Neste sentido, o Modelo Unificado de CD proposto pressupõe como processo as seguintes CD:

a) Criação/Geração de novo conhecimento dentro da empresa;

b) Recombinação, Reconfiguração, Combinação, Conversão e Transformação de conhecimentos já existentes dentro da empresa (ou em conjunto com conhecimento novo criado internamente, e que passa a se tornar existente);

c) Desenvolvimento de novo conhecimento em conjunto com agente (ou parceiro) externo;

d) Integração de um conhecimento externo existente a um conhecimento atual existente na empresa; 
e) Aquisição de um conhecimento externo existente para a empresa (cujo conhecimento era inexistente).

Em relação ao pressuposto na alínea "b", salienta-se que todas as nomenclaturas foram encontradas na literatura, mas são sinônimos para a mesma atividade que ocorre internamente na empresa, a partir de um ou mais conhecimentos existentes e que são relacionados. Isso pode ser traduzido, gerencialmente, em um processo produtivo que é transformado e sofre uma melhoria incremental (conhecimento interno e existente), ou a partir da combinação de competências de equipe de engenharia e de design que promova inovação de produto. Em essência, a capacidade de geração/criação está mais ligada ao processo de $\mathrm{P} \& \mathrm{D}$, tratando-se de um conhecimento totalmente novo para a empresa e esse capital intelectual tem influência na inovação (Hsu e Sabherwal, 2012).

Essa categorização genérica é importante, uma vez que abrange o sentido encontrado nas pesquisas, e expressos nas diversas manifestações práticas das Capacidades Dinâmicas. Por exemplo, a pesquisa de Killen e Hunt (2010), aponta que a Gestão de Portfólio de Projetos é uma capacidade dinâmica, com influência positiva na inovação de produto. Em essência, o papel da Gestão de Portfólio é combinar diferentes conhecimentos internos no sentido de maximizar o valor dos projetos selecionados e gerar alavancagem. Portanto, neste exemplo, a Capacidade Dinâmica genérica expressa é de combinação.

No entanto, sendo o conhecimento o elemento central, três CD citadas pelos autores, a de Aquisição, Assimilação e Aprendizado servem como link entre as demais capacidades de processo, para fins de coleta, interpretação e internalização. Já as capacidades de Perceber e Aproveitar Oportunidades (sensing and seizing), do Aproveitamento (leveraging) e da Imitação, pela definição dos autores, estão relacionadas mais a posturas do que a processos, portanto, caracterizar-se-iam como orientações da organização.

A primeira diz respeito ao posicionamento da empresa de modo favorável no ambiente competitivo para explorar novas oportunidades; a segunda ao nível de potencialização e incentivo que a empresa dá para os demais processos (conforme observado nos indicadores de Makkonen, Pohjola, Olkkonen e Koponen (2013); enquanto que a terceira é uma tipologia identificada por Denford (2013) e também elencada originalmente por Teece, Pisano e Shuen (1997). Entretanto, uma orientação para imitação nem sempre é benéfica para fins de desempenho em inovação, conforme já observado em outros estudos. Mas a orientação à imitação em si permite à empresa (dependendo do contexto) adquirir, assimilar e aprender podendo gerar inovações (uma empresa brasileira que copia um produto

Revista de Administração e Inovação, São Paulo, v.12, n.1, p.271-302, jan./mar. 2015. 
europeu, que atualmente não é vendido no Brasil, implementa uma inovação neste mercado em específico, conforme algumas abordagens).

E, por fim, as CD de Implantação (deploy), Síntese, Aplicação e Replicação não se caracterizam somente como processos, mas também como resultados (outcomes), ou a implantação desta "nova" competência, seja com base em conhecimento novo gerado (interno ou externo), seja em conhecimento existente (interno ou externo) e que são essenciais para que as CD se concretizem nos diferentes tipos de inovação (Liao et al. 2009).

Desta maneira, o modelo unificado em si busca explicar de que forma as CD ocorrem na empresa, a partir do conceito de Teece (2007), que voltou a redefinir as CD como capacidades relacionadas à organização de: (i) identificar e moldar oportunidades e ameaças, (ii) capturar oportunidades e (iii) manter competitividade por meio da ampliação, combinação, proteção e, quando necessário, reconfiguração dos ativos tangíveis e intangíveis ligadas ao negócio. Para isso, a empresa utiliza mecanismos que realizam a interface entre seu conhecimento e o conhecimento externo, e este é um aspecto central de entendimento do modelo.

Em relação ao conhecimento externo, a empresa pode simplesmente adquirir (absorver) ou desenvolver (combinar seu conhecimento com o de um parceiro externo). Esse intercâmbio de tecnologias e conhecimentos é crucial para a organização, principalmente em redes internacionais e a capacidade dinâmica de desenvolvimento se relaciona com a inovação (Lew et. al, 2013; Lee et. al 2011). Ainda Huang (2011) apresenta que há relações positivas entre essa capacidade de aquisição e inovação da empresa. Este conhecimento, absorvido para dentro das fronteiras da empresa, passará por um processo de assimilação ou de interpretação. Porém, o conhecimento somente será incorporado ao conhecimento da empresa a partir do momento em que houver a aprendizagem efetiva, seja por meio de um processo deliberado, planejado, seja advinda da experiência empresarial. Interpretar um conhecimento não implica necessariamente na internalização de sua aprendizagem. Inclusive, Marsh e Stock (2006) avaliaram e verificaram uma relação positiva entre a interpretação e o desempenho no processo de Desenvolvimento de Novos Produtos (DNP). Branzei (2006) argumenta que as capacidades dinâmicas são importantes para o sucesso da inovação de produto, justamente pois possibilitam a empresa a adquirir e assimilar conhecimento externo, transformar em conhecimento novo dentro da organização, em um processo que possibilita o desenvolvimento de novos ou melhorados produtos.

Ainda, a CD de Integração neste modelo está amparada em Makkoen, Pohjola, Olkkonen e Koponen (2013), que implica integrar um conhecimento interno e aprendido a um conhecimento assimilado externamente (seja via aquisição, seja via desenvolvimento). Esse posicionamento também

Revista de Administração e Inovação, São Paulo, v.12, n.1, p.271-302, jan./mar. 2015. 
é endossado para Yang (2012), já que a capacidade de integração envolve relacionar diferentes conhecimentos na empresa (na forma de skills, por exemplo), que sejam críticos para o desenvolvimento de um novo produto. A assimilação ainda é uma camada de tradução, que permite o conhecimento da firma ser integrado ao desenvolvimento (analisando-se o processo de forma reversa).

Já analisando dentro dos limites da empresa, esse conhecimento interno poderá sofrer processos de criação/geração de novo conhecimento (que retorna ao estoque central de conhecimento da organização), bem como poderá passar por processos de combinação, recombinação (Barrales-Molina et al., 2012) e que são essenciais para a regeneração da organização (Jarrat, 2008) e bem como para combinação (Zheng, Zhang, Wu e Du, 2011) . No entanto, caracteriza-se que a mudança só é efetivada a partir do momento que existe a implantação ou replicação deste conhecimento na empresa, gerando a inovação (que se torna agora um conhecimento da empresa). Todo este processo é mediado pelo sensing e seizing, que definem o posicionamento da empresa em olhar o ambiente externo, pelo aproveitamento (incentivo aos demais processos) e, dependendo do contexto, pela imitação, consistindo-se os três em orientações.

A partir desta perspectiva é que se buscou unificar tipologias mapeadas, agregando um caráter lógico de relacionamento entre tais elementos, e definindo as tipologias de Denford (2013), Makkonen, Pohjola, Olkkonen e Koponen (2013) e demais identificadas nos estudos, delimitando onde cada capacidade atua. A questão futura, então, é a proposição de testagem deste modelo em relação à inovação, e de que maneira as diferentes capacidades se relacionarão aos diferentes tipos de inovação e contextos (ambientes competitivos).

Isto posto, na Figura 2, apresenta-se o modelo proposto, o qual é sugerido como uma estrutura de análise ou um framework para o desenvolvimento de pesquisa futuras, o qual denominamos de Modelo Unificado das Capacidades Dinâmicas. 


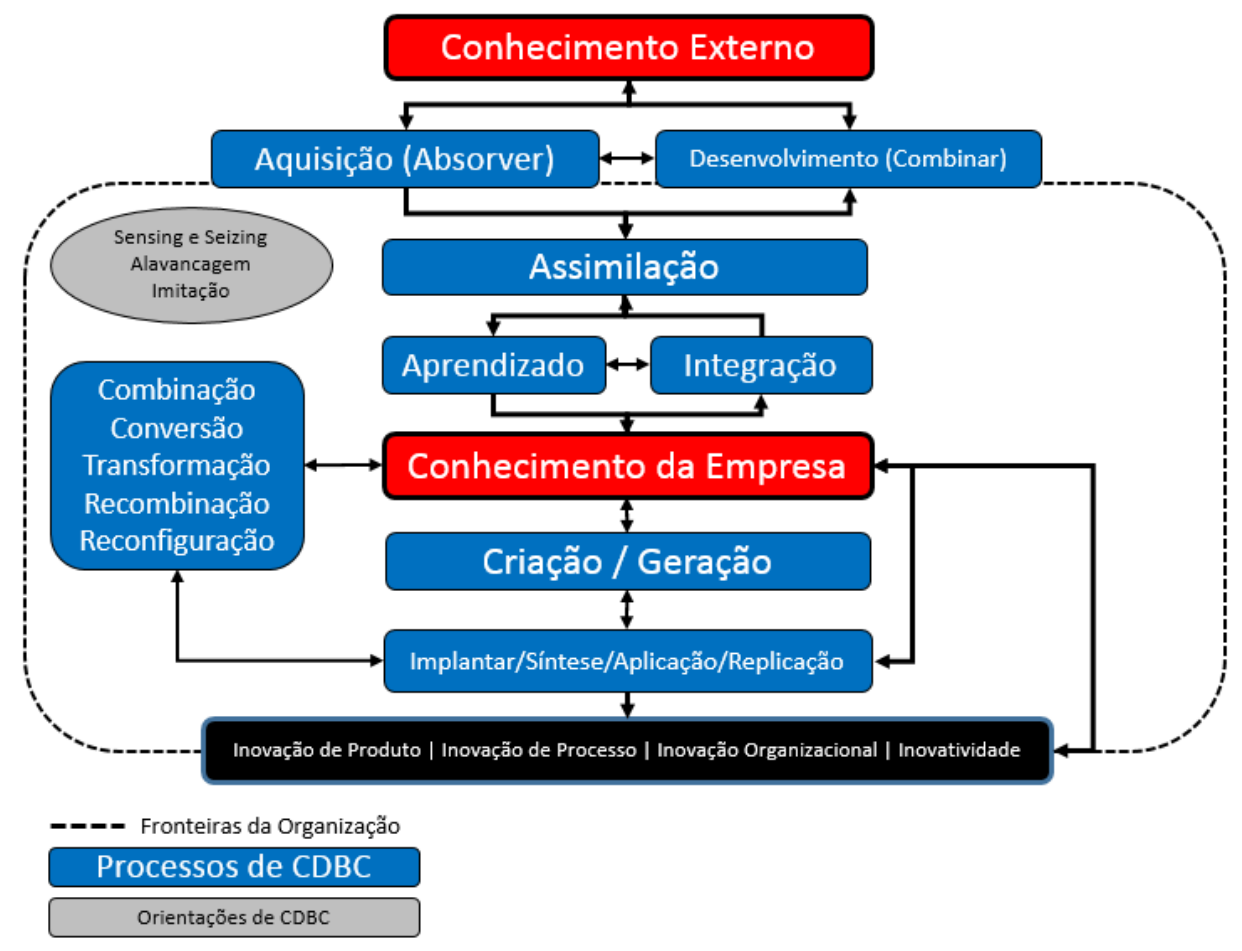

Figura 2: Modelo Unificado das Capacidades Dinâmicas

Ele diferencia-se da proposta de Teece (1997) não apenas pela representação visual das interações entre as $\mathrm{CDBC}$, mas também pela extensão de tipos de $\mathrm{CDBC}$ envolvidas, em relação à proposta original e pela fundamentação na VBC e não na VBR, a qual era a raiz teórica inicial das CD. Neste sentido, a perspectiva da VBC fornece uma melhor compreensão a partir da relação entre as CDBC com o conhecimento externo e interno da organização. É importante destacar que em 2014, Teece (2014) introduz um Framework das Capacidades Dinâmicas, no objetivo de esclarecer a definição deste tema.

Apresentado na Figura 3, ele elucida que as capacidades organizacionais direcionam a performance (lucratividade) da empresa, e elas estão associadas aos Recursos (VRIN - Valuables, Rares, Imperfectly imitable and Non-substitutable). Para Teece (2014), as capacidades dinâmicas fortes estão integradas à estratégia e presença (conjunta) de capacidades dinâmicas, recursos e estratégia é necessária para o sucesso financeiro no longo prazo. O autor aponta que as capacidades ordinárias (operações, administração, governança), precisam ser acessadas pela empresa, mas não necessariamente precisam ser de sua propriedade e gerenciar uma pletora de capacidades ordinárias pode desfavorecer as capacidades dinâmicas, não sendo estas por si só suficientes para o sucesso no longo prazo. Teece (2014) ressalta ainda que a efetividade das Capacidades Dinâmicas pode ser comprometida por má estratégia e quanto maior a diversidade e maior a taxa de mudança do ambiente de negócio, e maior a importância dos ativos intangíveis (incluindo conhecimento), mais crítica será a 
influência da boa estratégia e de fortes capacidades dinâmicas para o crescimento empresa e performance financeira.

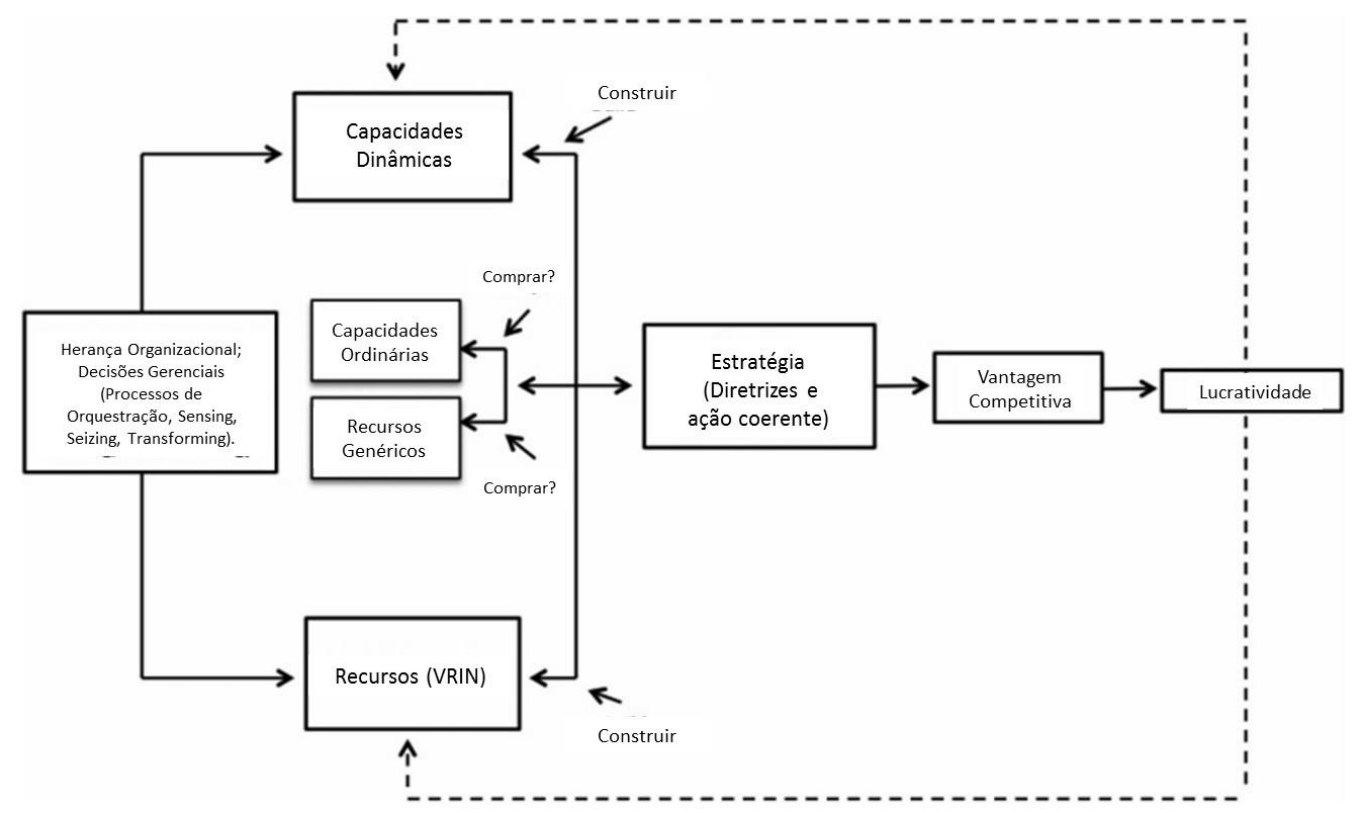

Figura 3: Framework das Capacidades Dinâmicas

Fonte: Teece (2014)

Nesta perspectiva, o framework de Teece (2014) introduz que em ambientes turbulentos e que necessitam de atividades intensivas de inovação (produto, processo, gestão), as capacidades dinâmicas associadas aos ativos intangíveis, como e o caso, o conhecimento, tornam-se mais críticas para o crescimento da empresa. Neste sentido, o framework deste estudo das CDBC conecta-se ao framework de maior nível Teece (2014) no elemento "Capacidades Dinâmicas", pois elucida e descreve as relações que ocorrem dentro deste limite.

Salienta-se que, neste primeiro momento, este framework possui a limitação de não apresentar relações causais e estatísticas entre cada dimensão, pois sua pretensão é propor uma relação analítica entre estas dimensões, de modo a instigar um debate sobre sua estrutura, e prover uma visão mais concreta acerca das $\mathrm{CD}$, que consistem em um conceito complexo e abstrato. É lógico, por exemplo, assumir que não pode haver uma ligação direta entre a capacidade de aquisição de conhecimento externo e a implantação de um conhecimento novo é algo que merece destaque. Ora, um conhecimento externo só poderá se transformar em conhecimento da empresa mediante questões de aquisição, assimilação, aprendizado e integração. É a partir desta base de conhecimento da empresa que os processos internos intrínsecos às $\mathrm{CD}$ poderão ser utilizados de forma a promover a inovação, seja ela de produto, processo, organizacional ou afetar o nível de inovatividade da empresa.

Evidentemente que, a partir desta perspectiva, emerge a provocação de uma agenda de pesquisa. Por exemplo, de que maneira essas capacidades (na perspectiva de processos) são mais ou menos 
desenvolvidas por tipo (perfil) de empresa e por tipo de inovação? Como as CD e a inovação são mediadas pelos tipos de orientações (sensing, imitação)? Contudo, a contribuição mais importante deste estudo é a convenção do conceito específico a cada uma das $\mathrm{CD}$, a partir da visualização de suas relações, e da sua interface entre o conhecimento da empresa e o conhecimento externo.

\section{CONCLUSÕES}

Este artigo teve como objetivo propor um framework de referência para a área, o Modelo Unificado das Capacidades Dinâmicas Baseadas em Conhecimento. Partindo da problemática da divergência da operacionalização de construtos, este estudo partiu da tipologia proposta por Denford (2013), e agregou demais relações testadas via estudos tipos survey de CDBC e inovação para construir um entendimento sistêmico das relações entre os tipos de CDBC existentes.

Adotando uma metodologia de seleção, dos 233 estudos que pesquisaram as CD e a Inovação, apenas 25 destes, de fato, resultaram como estudos do tipo survey, apresentando, portanto, estatisticamente a relação pesquisada, empiricamente, e com especifica delimitação dos construtos e indicadores. Com base em uma análise de conteúdo destes artigos, este trabalho identificou significativas divergências na operacionalização das Capacidades Dinâmicas associadas à Inovação, ainda que as relações encontradas fossem positivas.

A partir desta lacuna identificada, foi realizada uma proposta de Modelo Unificado de Capacidades Dinâmica integrando a tipologia proposta por Denford (2013), a escala validada de Makkonen, Pohjola, Olkkonen e Koponen (2013) e as dimensões das CD que apresentaram relações estatísticas significantes com a Inovação de 25 estudos, mas que não haviam sido contempladas por estes autores. Considera-se que um framework de referência é uma proposição teórica importante para o amadurecimento da definição de cada dimensão, uma vez que a sua nomenclatura depende do seu papel e suas relações neste sistema.

Com isso, este estudo busca propor uma agenda de pesquisa futura, instigando os pesquisadores a amadurecerem os resultados intrínsecos à relação existentes entre as CD e o Desempenho de Inovação a partir do modelo proposto, mas principalmente, da clara definição dos constructos utilizados e da sua forma de operacionalização. Sem isto, sempre existirá uma dificuldade de desenvolver meta-análises de modo a compreender os efeitos agregados que este importante conceito possui sobre o desempenho de inovação e das empresas.

Revista de Administração e Inovação, São Paulo, v.12, n.1, p.271-302, jan./mar. 2015. 
No que tange às limitações do estudo, ressalta-se que a identificação dos tipos de CD teve como base uma amostra de artigos obtidos via o acesso aos periódicos em bases indexadas. Salienta-se que determinados trabalhos, cujos títulos sugeriam uma potencial investigação do tipo survey com a relação entre CD e inovação, não estavam disponíveis para download, e isto interferiu na quantidade de CD mapeadas.

Contudo, como a tipologia de CD base para o modelo proposto teve como base a fundamentação em trabalhos síntese publicados em periódicos de referência, tal como o Journal of Knowledge Management, observa-se que as CD já identificadas na literatura tenham sido atendidas na sua totalidade. Ainda, como o objetivo da pesquisa não era o de realizar uma inferência estatística, nem uma meta-análise, tampouco expressar conclusões em termos das CD mais pesquisadas, mas sim promover uma inferência analítica de um modelo unificado sustentada em proposições lógicas, evidencia-se que esta limitação trata-se na verdade de uma oportunidade de agenda de pesquisa futura a partir do framework proposto.

Um aspecto que merece destaque é o de que novas CD que venham a ser identificadas por novos pesquisadores, e de que forma elas se relacionam com este framework também é algo que pode vir a gerar interesses de pesquisa. $\mathrm{O}$ outro aspecto é que o modelo expressa as relações entre as $\mathrm{CD}$, considerando o relacionamento existente entre o conhecimento da empresa e o conhecimento externo a ela. Portanto, é esperado, por efeito lógico, que não haja uma relação direta entre determinadas capacidades (aquisição de conhecimento externo e replicação do conhecimento interno, por exemplo, uma vez que entre estas duas capacidades há capacidades de assimilação e de aprendizado que as mediam), mas isso não exclui a hipótese de efeitos indiretos.

\section{REFERÊNCIAS}

Acedo, F. J., Barroso, C., \& Galan, J. L. (2006). The resource-based theory: dissemination and main trends. Strategic Management Journal, 27(7), 621-636.

Bardin, L. (2009). Análise de conteúdo. Lisboa: Edições 70.

Barrales-Molina, V., Bustinza, O. F., \& Gutiérrez-Gutiérrez, L. J. (2012). Explaining the causes and effects of dynamic capabilities generation: a multiple-indicator multiple-cause modeling approach. British Journal of Management, 24(2), 571-591.

Branzei, O., \& Vertinsky, I. (2006). Strategic pathways to product innovation capabilities in SMEs. Journal of Business Venturing, 21(1), 75-105. 
Brühl, R., Horch, N., \& Osann, M. (2010). Improving integration capabilities with management control. European Journal of Innovation Management, 13(4), 385-408.

Camisón, C., \& Monfort-Mir, V. M. (2012). Measuring innovation in tourism from the Schumpeterian and the dynamic-capabilities perspectives. Tourism Management, 33(4), 776-789.

Canoa, C. R., Carrillat, F. A., \& Jaramillo, F. (2004). A meta-analysis of the relationship between market orientation and business performance: evidence from five continents. International Journal of Research in Marketing, 21, 179-200.

Cepeda, G., \& Vera, D. (2007). Dynamic capabilities and operational capabilities: a knowledge management perspective. Journal of Business Research, 60(3), 426-437.

Cheng, C. C. J., \& Chen, J. S. (2013). Breakthrough innovation: the roles of dynamic innovation capabilities and open innovation activities. Journal of Business \& Industrial Marketing, 28(5), 444454.

Conner, K. R., \& Prahalad, C. K. (1996). A resource-based theory of the firm: knowledge vs opportunism. Organization Science, 7(5), 477-501.

Delmas, M. A. (2002). Innovating against European rigidities institutional environment and dynamic capabilities. Journal of High Technology Management Research, 13, 19-43.

Denford, J. S. (2013). Building knowledge: developing a knowledge-based dynamic capabilities typology. Journal of Knowledge Management, 17(2), 175-194.

Eisenhardt, K. M., \& Martin, J. A. (2000). Dynamic capabilities: what are they? Strategic Management Journal, 21(10/11), 1.105-1.121.

Fleury, A., Fleury, M. T. L., \& Borini, F. M. (2013). The Brazilian multinationals' approaches to innovation. Journal of International Management, 19(3), 260-275.

García-Morales, V. J., Jiménez-Barrionuevo, M. M., \& Gutiérrez-Gutiérrez, L. (2012). Transformational leadership influence on organizational performance through organizational learning and innovation. Journal of Business Research, 65(7), 1.040-1.050.

García-Morales, V. J., Lloréns-Montes, F. J., \& Verdú-Jover, A. J. (2007). Influence of personal mastery on organizational performance through organizational learning and innovation in large firms and SMEs. Technovation, 27(9), 547-568.

Gibbs, G. (2008). Analyzing qualitative data. Thousand Oaks: Sage Publications.

Grant, R. M. (1996). Toward a knowledge-based theory of the firm. Strategic Management Journal, 17(Special Issue), 109-122.

Hambrick, D. C. (1984). Taxonomic approaches to studying strategy: some conceptual and methodological issues. Journal of Management, 10(1), 27-41.

Hao, J., Ilan, A., \& Yu, C. (2011). Environmental dynamism, innovation, and dynamic capabilities: the case of China. Journal of Enterprising Communities: People and Places in the Global Economy, 5(2), 131-144.

Revista de Administração e Inovação, São Paulo, v.12, n.1, p.271-302, jan./mar. 2015. 
Helfat, C. E., \& Peteraf, M. A. (2003). The dynamic resource-based view: capability lifecycles. Strategic Management Journal, 24(10), 997-1.010.

Hennink, M., Hutter, I., \& Bailey, A. (2011). Qualitative research methods. Thousand Oaks: Sage Publications.

Hodgkinson, G. P., \& Healey, M. P. (2011). Psychological foundations of dynamic capabilities: reflexion and reflection in strategic management. Strategic Management Journal, 32(13), 1.500-1.516.

Hofmann, K. H., Theyel, G., \& Wood, C. H. (2012). Identifying firm capabilities as drivers of environmental management and sustainability practices - evidence from small and medium-sized manufacturers. Business Strategy and the Environment, 21(8), 530-545.

Hsu, I. C., \& Sabherwal, R. (2012). Relationship between intellectual capital and knowledge management: an empirical investigation. Decision Sciences, 43(3), 489-524.

Huang, K. F. (2011). Technology competencies in competitive environment. Journal of Business Research, 64(2), 172-179.

Im, S., Montoya, M. M., \& Workman, J. P. (2013). Antecedents and consequences of creativity in product innovation teams. Journal of Product Innovation Management, 30(1), 170-185.

Jarratt, D. (2008). Testing a theoretically constructed relationship management capability. European Journal of Marketing, 42(9/10), 1.106-1.132.

Junell, J., \& Ståhle, P. (2011). Measuring organizational renewal capability: case training service business. Competitiveness Review: An International Business Journal incorporating Journal of Global Competitiveness, 21(3), 247-268.

Killen, C. P., \& Hunt, R. A. (2010). Dynamic capability through project portfolio management in service and manufacturing industries. International Journal of Managing Projects in Business, 3(1), 157-169.

Kirca, A. M., Jayachandran, S., \& Bearden, W. O. (2005). Market orientation: a meta-analytic review and assessment of its antecedents and impact on performance. Journal of Marketing, 69(2), 24-41.

Kogut, B., \& Zander, U. (1992). Knowledge of the firm, combinative capabilities, and the replication of technology. Organization Science, 3(3), 383-397.

Kohlbacher, M. (2013). The impact of dynamic capabilities through continuous improvement on innovation: the role of business process orientation. Knowledge and Process Management, 20(2), 7176.

Lee, H., \& Kelley, D. (2008). Building dynamic capabilities for innovation: an exploratory study of key management practices. $R \& D$ Management, 38(2), 155-168.

Lee, P. Y., Lin, H. T., Chen, H. H., \& Shyr, Y. H. (2011). Dynamic capabilities exploitation of market and hierarchy governance structures: an empirical comparison of Taiwan and South Korea. Journal of World Business, 46(3), 259-370. 
Lew, Y. K., Sinkovics, R. R., \& Kuivalainen, O. (2013). Upstream internationalization process: roles of social capital in creating exploratory capability and market performance. International Business Review, 22(6), 1.101-1.120.

Liao, J. , Kickul, J. R., \& Ma, H. (2009). Organizational dynamic capability and innovation: an empirical examination of internet firms. Journal of Small Business Management, 47(3), 263-286.

Makkonen, H., Pohjola, M., Olkkonen, R., \& Koponen, A. (2013). Dynamic capabilities and firm performance in a financial crisis. Journal of Business Research, 67(1), 2.707-2.719.

March, J. G. (1991). Exploration and exploitation in organizational learning. Organization Science, 2(1), 71-87.

Marsh, S. J., \& Stock, G. N. (2006). Creating dynamic capability: the role of intertemporal integration, knowledge retention, and interpretation. Journal of Product Innovation Management, 23(5), 422-436.

Nelson, R. R., \& Winter, S. G. (1982). An evolutionary theory of economic change. Cambridge: Belknap Press/Harvard University Press.

Ray, G., Barney, J. B., \& Muhanna, W. A. (2004). Capabilities, business processes, and competitive advantage: choosing the dependent variable in empirical tests of the resource-based view. Strategic Management Journal, 25(1), 23-37.

Remler, D. K., \& Van Ryzin, G. G. (2011). Research methods in practice: strategies for description and causation. Thousand Oaks: Sage Publications.

Rothaermel, F. T., \& Alexandre, M. T. (2009). Ambidexterity in technology sourcing: the moderating role of absorptive capacity. Organization Science, 20(4), 759-780.

Schreier, M. (2012). Qualitative content analysis in practice. London: Sage Publications.

Scott, G., \& Garner, R. (2013). Doing qualitative research: designs, methods, and techniques. $1^{\text {st }}$ edition. Upper Saddle River: Pearson.

Shoham, A., Rose, G. M., \& Kropp, F. (2005). Market orientation and performance: a meta-analysis. Marketing Intelligence \& Planning, 23(5), 435-454.

Smart, P., Bessant, J., \& Gupta, A. (2007). Towards technological rules for designing innovation networks: a dynamic capabilities view. International Journal of Operations \& Production Management, 27(10), 1.069-1.092.

Stefano, G; Peteraf, M; Verona, G. (2014). The organizational drivetrain: a road to integration of dynamic capabilities research. The Academy of Management Perspectives, 28(4), 307-327.

Teece, D. J., Pisano, G., \& Shuen, A. (1997). Dynamic capabilities and strategic management. Strategic Management Journal, 18(7), 509-533.

Teece, D. (2007). Explicating dynamic capabilities: the nature and microfoundations of (sustainable) enterprise performance. Strategic Management Journal, v. 1350, n. August, p. 1319-1350.

Teece, D (2014). The foundations of enterprise performance: dynamic and ordinary capabilities in an (economic) theory of firms. The Academy of Management Perspectives, 28(4), 328-352. 
Teece, D.J., 2009. Dynamic Capabilities and Strategic Management. Oxford University Press, NY.

Triguero, A., \& Córcoles, D. (2013). Understanding innovation: an analysis of persistence for Spanish manufacturing firms. Research Policy, 42(2), 340-352.

Uhlaner, L. M., Van Stel, A., Duplat, V., \& Zhou, H. (2012). Disentangling the effects of organizational capabilities, innovation and firm size on SME sales growth. Small Business Economics, $1-55$.

Verona, G., \& Ravasi, D. (2003). Unbundling dynamic capabilities: an exploratory study of continuous product innovation. Industrial and Corporate Change, 12(3), 577-606.

Von Krogh, G., Nonaka, I., \& Aben, M. (2001). Making the most of your company's knowledge: a strategic framework. Long Range Planning, 34(4), 421-439.

Winter, S. G. (2000). The satisficing principle in capability learning. Strategic Management Journal, 21(10/11), 981-996.

Wu, L. Y. (2006). Resources, dynamic capabilities and performance in a dynamic environment: perceptions in Taiwanese IT enterprises. Information \& Management, 43(4), 447-454.

Yang, J. (2012). Innovation capability and corporate growth: an empirical investigation in China. Journal of Engineering and Technology Management, 29(1), 34-46.

Zahra, S. A., \& George, G. (2002). Absorptive capacity: a review, reconceptualization and extension. Academy of Management Review, 27(2), 213-240.

Zahra, S. A., Sapienza, H. J., \& Davidsson, P. (2006). Entrepreneurship and dynamic capabilities: a review, model and research agenda. Journal of Management Studies, 43(4), 917-955.

Zheng, S., Zhang, W., Wu, X., \& Du, J. (2011). Knowledge- based dynamic capabilities and innovation in networked environments. Journal of Knowledge Management, 15(8), 1.035-1.051.

Zollo, M., \& Winter, S. G. (2002). Deliberate learning and the evolution of dynamic capabilities. Organization Science, 13(3), 339-351. 


\title{
DYNAMIC CAPABILITIES AND INNOVATION PERFORMANCE
}

\begin{abstract}
The Dynamic Capabilities (DC) are one of the most important and researched topic in the Strategy field. However, there is some lack of uniformity about your definition and distinguished dimensions are used when this theme is presented by different authors. This research aim to propose an analytic framework of Knowledge-Based Dynamic Capabilities (KDBC) and types of innovation, developed from the synthesis of survey studies that relate $\mathrm{KDBC}$ and Innovation Performance. From Denford (2013) categories proposal, and using content analysis strategy, this study identified the associated dimensions, how they were operationalized and the type of relationship. As result, this paper introduces a framework to better understand the relationship between the different types of Knowledge-Based Dynamic Capabilities and Innovation, and can guide future research in the field.
\end{abstract}

Key words: KBV - Knowledge-based View; Dynamic capabilities; Knowledge-based dynamic capabilities; Resources; Innovation; Innovation performance.

Data do recebimento do artigo: 01/06/2014

Data do aceite de publicação: 26/03/2015

Revista de Administração e Inovação, São Paulo, v.12, n.1, p.271-302, jan./mar. 2015. 
Apêndice - Relação de Trabalhos Utilizados no Presente Estudo

\begin{tabular}{|c|c|c|}
\hline $\mathbf{N}$. & $\begin{array}{c}\text { Ano da Publicação dos } \\
\text { Trabalhos } \\
\end{array}$ & Autores \\
\hline 1 & 2002 & Delmas \\
\hline 2 & 2006 & Branzei e Vertinsky \\
\hline 3 & 2006 & Marsh e Stock \\
\hline 4 & 2006 & $\mathrm{Wu}$ \\
\hline 5 & 2007 & García-Morales, Lloréns-Montes e Verdú-Jover \\
\hline 6 & 2008 & Jarratt \\
\hline 7 & 2009 & Liao, Kickul e Ma \\
\hline 8 & 2010 & Killen e Hunt \\
\hline 9 & 2011 & Hao, Ilan e Yu \\
\hline 10 & 2011 & Huang \\
\hline 11 & 2011 & Junell e Ståhle \\
\hline 12 & 2011 & Lee, Lin, Chen e Shyr \\
\hline 13 & 2011 & Zheng, Zhang, Wu e Du \\
\hline 14 & 2012 & Barrales-Molina, Bustinga e Gutiérres-Gutiérres \\
\hline 15 & 2012 & $\begin{array}{c}\text { García-Morales, Jiménez-Barrionuevo e } \\
\text { Gutiérres-Gutiérres }\end{array}$ \\
\hline 16 & 2012 & Hsu e Sabherwal \\
\hline 17 & 2012 & Uhlaner, Van Stel, Duplat e Zhou \\
\hline 18 & 2012 & Yang \\
\hline 19 & 2013 & Cheng e Chen \\
\hline 20 & 2013 & Fleury, Fleury e Borini \\
\hline 21 & 2013 & Im, Montoya e Workman \\
\hline 22 & 2013 & Kohlbacher \\
\hline 23 & 2013 & Lew, Sinkovics e Kuivalainen \\
\hline 24 & 2013 & Makkonen, Pohjola, Olkkonen e Koponen \\
\hline 25 & 2013 & Triguero e Córcoles \\
\hline
\end{tabular}

Agradecimento: Agradecemos ao CNPq - Conselho Nacional de Desenvolvimento Científico e Tecnológico por financiar este projeto de pesquisa. 